\title{
Coastal sources, sinks and strong organic complexation of dissolved cobalt within the US North Atlantic GEOTRACES transect GA03
}

\author{
Abigail E. Noble ${ }^{1, \mathrm{a}}$, Daniel C. Ohnemus ${ }^{1, \mathrm{~b}}$, Nicholas J. Hawco ${ }^{1}$, Phoebe J. Lam ${ }^{1, \mathrm{c}}$, and Mak A. Saito ${ }^{1}$ \\ ${ }^{1}$ Woods Hole Oceanographic Institution, Woods Hole, MA, USA \\ anow at: Gradient, 20 University Road, Cambridge, MA, USA \\ b now at: Bigelow Laboratory for Ocean Sciences, East Boothbay, ME, USA \\ c now at: University of California Santa Cruz, Santa Cruz, CA, USA
}

Correspondence to: Mak A. Saito (msaito@whoi.edu)

Received: 24 November 2016 - Discussion started: 1 December 2016

Revised: 27 March 2017 - Accepted: 19 April 2017 - Published: 2 June 2017

\begin{abstract}
Cobalt is the scarcest of metallic micronutrients and displays a complex biogeochemical cycle. This study examines the distribution, chemical speciation, and biogeochemistry of dissolved cobalt during the US North Atlantic GEOTRACES transect expeditions (GA03/3_e), which took place in the fall of 2010 and 2011. Two major subsurface sources of cobalt to the North Atlantic were identified. The more prominent of the two was a large plume of cobalt emanating from the African coast off the eastern tropical North Atlantic coincident with the oxygen minimum zone (OMZ) likely due to reductive dissolution, biouptake and remineralization, and aeolian dust deposition. The occurrence of this plume in an OMZ with oxygen above suboxic levels implies a high threshold for persistence of dissolved cobalt plumes. The other major subsurface source came from Upper Labrador Seawater, which may carry high cobalt concentrations due to the interaction of this water mass with resuspended sediment at the western margin or from transport further upstream. Minor sources of cobalt came from dust, coastal surface waters and hydrothermal systems along the Mid-Atlantic Ridge. The full depth section of cobalt chemical speciation revealed near-complete complexation in surface waters, even within regions of high dust deposition. However, labile cobalt observed below the euphotic zone demonstrated that strong cobalt-binding ligands were not present in excess of the total cobalt concentration there, implying that mesopelagic labile cobalt was sourced from the remineralization of sinking organic matter. In the upper water column, correlations were observed between total cobalt and phosphate, and between labile cobalt and phosphate,
\end{abstract}

demonstrating a strong biological influence on cobalt cycling. Along the western margin off the North American coast, this correlation with phosphate was no longer observed and instead a relationship between cobalt and salinity was observed, reflecting the importance of coastal input processes on cobalt distributions. In deep waters, both total and labile cobalt concentrations were lower than in intermediate depth waters, demonstrating that scavenging may remove labile cobalt from the water column. Total and labile cobalt distributions were also compared to a previously published South Atlantic GEOTRACES-compliant zonal transect (CoFeMUG, GAc01) to discern regional biogeochemical differences. Together, these Atlantic sectional studies highlight the dynamic ecological stoichiometry of total and labile cobalt. As increasing anthropogenic use and subsequent release of cobalt poses the potential to overpower natural cobalt signals in the oceans, it is more important than ever to establish a baseline understanding of cobalt distributions in the ocean.

\section{Introduction}

Cobalt is the scarcest of biologically utilized metals and has a complex marine biogeochemical cycle. The small inventory of oceanic cobalt is maintained by a combination of supply mechanisms, including sedimentary, aeolian, riverine/coastal, and hydrothermal inputs. In particular, the high abundances of cobalt that have been observed as major plumes within the low-oxygen waters of major oxygen min- 
imum zones (OMZs) of the South Atlantic and South Pacific (Hawco et al., 2016; Noble et al., 2012), and from more limited datasets from the North Pacific (Ahlgren et al., 2014; Saito et al., 2004, 2005), are likely due to reductive dissolution and advection of sedimentary sources in regions with low-oxygen bottom water sediment-water interfaces (Heggie and Lewis, 1984). Coastal and island sources in oxygenated environments have also been observed, for example, off the North American continental shelf (Saito and Moffett, 2002) and near the Kerguelen Islands (Bown et al., 2012a). While there is limited information regarding the riverine and coastal fluxes of particulate and dissolved cobalt to the oceans, earlier datasets show a significant "desorbable" load of particulate cobalt as well as estuarine sources of organic cobalt complexes (Kharkar et al., 1968; Zhang et al., 1990). The contribution of cobalt from dust has been more difficult to directly observe because of the small amounts of cobalt present in dust relative to iron, with a $\mathrm{Co}: \mathrm{Fe}$ ratio in crustal material of $1: 2600$ (equivalent to $30 \mathrm{ppm}$ per $3-8 \%$ Fe by mass; Taylor and McLennan, 1985), and its likely rapid utilization in the photic zone. Nevertheless, laboratory and field studies have shown evidence for potentially significant dust contributions to upper water column cobalt from anthropogenic and natural dust sources (Shelley et al., 2015; Thuróczy et al., 2010). While cobalt has been found to be enriched in end-member hydrothermal fluids up to $2570 \mathrm{nM}$ at TAG in the North Atlantic Mid-Atlantic Ridge (Metz and Trefrey, 2000), input is thought to be relatively localized to near-vent environments due to rapid removal by precipitating manganese and iron oxyhydroxides.

In addition to these natural sources, there has recently been tremendous growth in the economic market for cobalt through the use of lithium batteries and their cobalt lithium oxide cathode (Scrosati and Garche, 2010). This makes up a relatively new and large mobile reservoir of cobalt throughout the world within electronics, homes, powerplants, cars, and other devices. The environmental impacts of cobalt pollution via mining, smelting, and inappropriate disposal of batteries will likely significantly increase in the future (Banza et al., 2009). A baseline assessment of riverine and oceanic cobalt distributions is critical to inform the development of sustainable economies with regard to trace metal biogeochemical cycles and the future study of the industrial ecology of cobalt.

The chemical speciation of cobalt is dynamic in the oceans. Cobalt is a redox active metal that tends to be strongly bound to organic complexes in the upper water column, though some fraction of dissolved cobalt remains unbound or weakly bound as labile cobalt (presumably as $\mathrm{Co}(\mathrm{II})$ ) below the euphotic zone in intermediate and deep waters. In the photic zone and upper water column, saturating concentrations of cobalt-binding ligands are often observed, particularly in oligotrophic regimes where cyanobacteria are well represented (Saito and Moffett, 2001; Saito et al., 2005). These ligands are extraordinarily strong, with con- ditional stability constants on the order of $>10^{16.8}$ (Bown et al., 2012b; Saito et al., 2005), which is significantly higher than those for other transition metals such as iron $\left(\mathrm{FeL}_{1}\right)$, for which measured stability constants are on the order of $10^{13.1}$ (Rue and Bruland, 1997; Buck et al., 2015). To achieve stability constants in this range, the cobalt-ligand complexes, measured by the difference between the total cobalt and the labile cobalt, almost certainly have a redox state of $\mathrm{Co}(\mathrm{III})$, and are inert to back reaction with added competitive ligands (Baars and Croot, 2015; Saito and Moffett, 2001; Saito et al., 2005). Moreover, strong cobalt-binding ligands have not been observed in great excess of the total cobalt. The strong conditional stability constant of the cobalt-binding ligands is consistent with a $\mathrm{Co}$ (III) redox state, which is literally used as a textbook example of an inert metal redox state (Lippard and Berg, 1994). With Co(III) being highly insoluble in inorganic form, it is likely too scarce to coordinate in any appreciable quantities with strong ligands in seawater, and its source is presumed to be intracellular biosynthesis via binding of $\mathrm{Co}$ (II) by the enzyme cobaltochelatase and insertion into a small molecule ligand. In contrast, the labile pool of cobalt in seawater appears to be Co(II) based on its lability with added competitive ligands. Moreover, Co(II) would be in competition with $\mathrm{Ni}$ (II) for binding by any strong ligands, where nickel has a higher affinity for multi-dentate ligands than cobalt (Saito and Moffett, 2001; Saito et al., 2005). Nickel tends to be present in great excess of cobalt, often with a large labile fraction, and hence the lack of any observed excess cobalt-binding ligand can be explained by its preferential binding to nickel (Saito and Moffett, 2001; Saito et al., 2005).

The structure of strong, cobalt ligands in seawater is currently unknown, but may be related to precursors or degradation products of vitamin $\mathrm{B}_{12}$, a cobalt-containing biomolecule. This complexation by strong organic ligands likely protects and/or slows cobalt from scavenging (Saito and Moffett, 2001), as is similarly thought to occur for iron (Johnson et al., 1997). These ligands also have a strong influence on the bioavailability of cobalt to microorganisms (Saito et al., 2002) and the resultant microbial and phytoplankton ecology (Saito and Goepfert, 2008; Saito et al., 2010; Sunda and Huntsman, 1995). While the strongly complexed cobalt is likely somewhat protected from scavenging, the presence of labile cobalt in much of the oceanic water column should make that fraction particularly vulnerable to scavenging processes. Because complexed and labile cobalt have different physicochemically driven cycles but are inherently linked by biological transformations, cobalt speciation must be considered in efforts to fully understand the biogeochemical cycling of cobalt in the oceans.

In recent years, there has been an emergence of ocean studies with high-throughput analyses of dissolved cobalt (Bown et al., 2011, 2012b; Dulaquais et al., 2014a, b; Noble et al., 2012) and labile cobalt (Noble et al., 2012), as a part of the prelude to, or as part of, the international GEOTRACES pro- 
gram (Boyle et al., 2015). These studies have considerably increased the available datasets on dissolved cobalt in the oceans and have contributed to an understanding of cobalt cycling across several diverse biogeochemical regimes. The Benguela Upwelling system appears to be a major source of dissolved Co to the South Atlantic Ocean, with a plume extending more than halfway across the basin. Cobalt was also observed to be scavenged more slowly than other hybrid-type metals like Fe and Mn, likely due to its slower oxidation kinetics and lower oxygen abundances in the OMZ (Noble et al., 2012). Additional datasets have explored the distribution and speciation of cobalt in the Atlantic and Pacific sectors of the Southern Ocean (Bown et al., 2011; Ellwood, 2008); the Ross Sea and McMurdo Sound of Antarctica (including seasonal variability and under ice early spring conditions) (Noble et al., 2013; Saito et al., 2010); the eastern tropical North Pacific and Costa Rica Dome (Ahlgren et al., 2014); the eastern tropical North Atlantic (Baars and Croot, 2015); near the Bermuda, Hawaiian, and Kerguelen islands (Bown et al., 2012a; Noble et al., 2008; Shelley et al., 2012); and throughout meridional transects of the western Atlantic Ocean (Dulaquais et al., 2014a, b; Shelley et al., 2016). The establishment of these high-throughput sampling and analytical methods for cobalt, largely in response to the GEOTRACES program, has greatly improved our ability to assess and monitor the biogeochemistry of this key micronutrient throughout the global oceans. In fact, before 1990, there were fewer than 200 dissolved cobalt measurements throughout the entirety of the oceans.

In this study, we examined the distributions of total dissolved cobalt and labile cobalt in the North Atlantic during the US GEOTRACES North Atlantic transect (GA03/3_e). The resulting ocean section from this study is compared to the GEOTRACES-compliant zonal section in the South Atlantic Ocean (the CoFeMUG expedition, GAc01; Noble et al., 2012). The North Atlantic is an ideal region for the study of biogeochemical processes given the major contributions from aeolian dust deposition from the Sahara and Northern Hemisphere anthropogenic sources, proximity to coastal and continental sources, strong hydrothermal sources associated with the Mid-Atlantic Ridge, and recently formed North Atlantic Deepwater. Moreover, based on previous studies in the South Atlantic, the Mauritanian Upwelling region and the associated OMZ were expected to also exert strong influences on the distribution of cobalt in the ocean interior. Two companion papers describe this large dataset. The first describes the methodology, intercalibration and preservation, oceanic distributions, chemical speciation, and major sources of cobalt to the North Atlantic Ocean (this study). The second paper examines the ecological stoichiometry of cobalt in zonal transects of the North and South Atlantic Ocean (Saito et al., 2017).

\section{Methods}

Samples were collected along the US GEOTRACES North Atlantic transect, GA03/3_e (chief scientists: William Jenkins, Ed Boyle, and Greg Cutter). This transect (Fig. 1) was sampled in two legs aboard the R/V Knorr: USGT10 (14 October 2010-3 November 2010; GA03_e) and USGT11 (4 November 2011-14 December 2011; GA03). The first leg (USGT10) departed from Lisbon, Portugal, and followed a transect southward, sampling Mediterranean Outflow Water (MOW) and concluding with a short westward transect along $17.4^{\circ} \mathrm{N}$, crossing the northern reach of the OMZ associated with the Mauritanian Upwelling system. This leg concluded at Station TENATSO at $24.5^{\circ} \mathrm{W}$ (USGT10-12). The second leg (USGT11) departed from Woods Hole, MA, and sampled west to east, from seasonally productive New England coastal waters, to shelf and slope waters, crossing the deep western boundary current (DWBC) and the Gulf Stream along the repeat hydrography section, Line W. After occupying the Bermuda Atlantic Time-Series station (BATS), the subsequent stations were sampled across the oligotrophic Sargasso Sea, the North Atlantic Subtropical Gyre, and the Mid-Atlantic Ridge hydrothermal TransAtlantic Geotraverse (TAG) site at an approximately $3^{\circ}$ longitudinal spacing. The second leg concluded with a reoccupation of Station TENATSO (USGT11-24).

\subsection{Sample collection}

Samples were collected using the Old Dominion University GEOTRACES carousel on both the 2010 expedition (USGT10) and the 2011 expedition (USGT11). Following the retrieval of the carousel, the pre-conditioned, Tefloncoated Go-Flo bottles were moved to the GEOTRACES Program class-100 trace metal clean van, pressurized with HEPA filtered air, filtered through $0.2 \mu \mathrm{m}$ Acropak filters in accordance with published methods (Cutter and Bruland, 2012), and immediately refrigerated. Further information regarding deployment of the GEOTRACES carousel can be found on the GEOTRACES website and in the GEOTRACES cookbook (www.GEOTRACES.org). Samples were also collected using the surface-towed fish. These samples were collected by suspending the towed fish off the starboard side with a boom, and sampled water at approximately $2 \mathrm{~m}$ depth using a Teflon diaphragm pump following the GEOTRACES Program Cookbook sampling recommendations.

Sample storage bottles were prepared by soaking overnight in the acidic detergent Citranox, rinsed thoroughly with Milli-Q water (Millipore), filled with $10 \% \mathrm{HCl}$ to soak for 10 days (Baker Instra-analyzed $\mathrm{HCl}$ ), rinsed thoroughly with Milli-Q water adjusted to $\mathrm{pH} 2$, and double-bagged, empty. Samples were kept in clean and rinsed $60 \mathrm{~mL}$ LDPE bottles and stored for either a short time $(<7$ days $)$ at $4{ }^{\circ} \mathrm{C}$ and double-bagged prior to analysis or for a longer time (640 days) at $4{ }^{\circ} \mathrm{C}$, double-bagged with gas-absorbing satchels 
and with the outer bag heat-sealed to allow for longerterm sample preservation by removal of oxygen. The gasabsorbing satchels were iron-free, obtained from Mitsubishi Gas Chemical (model RP-3K), and each satchel was rated to absorb $60 \mathrm{~mL}$ of $\mathrm{O}_{2}$ per $300 \mathrm{~mL}$ of air. Each heat-sealed bag (Ampac ${ }^{\mathrm{TM}}$ Flexibles SealPAK heavy-duty pouches, clear polyester $4.5 \mathrm{mil}$ ) held 6-7 $60 \mathrm{~mL}$ LDPE sample bottles and 3-4 gas-absorbing satchels. The satchels come in impermeable, vacuum-sealed bags of 25 . It would take a few days to use a full bag of 25 satchels, so the bags were expended of air and re-heat-sealed after the required number of satchels were removed in order to limit the exposure of the unused satchels to air. A heat sealer (Kapak by Ampac) was used to seal each bag. After allowing the heat sealer to heat up for $3 \mathrm{~min}$, the bags were sealed by lining up the open ends of the bag in the heat sealer and sealing for 1-2 s. When samples were ready to be analyzed, the bags were cut open and all samples in the bag were analyzed within a week. Both labile and total dissolved cobalt were analyzed from this sample bottle, and the sample identifier is the allocated GEOTRACES number.

\subsection{Total dissolved and labile cobalt analyses}

Concentrations of total dissolved and labile cobalt during USGT10 were determined shipboard using a previously described cathodic stripping voltammetry (CSV) method (Saito and Moffett, 2001; Saito et al., 2004). Measurements were made using the Eco-Chemie $\mu$ AutolabIII systems connected to Metrohm 663 VA Stands equipped with hanging mercury drop electrodes and Teflon sampling cups within 7 days of sampling on double-bagged samples that were kept in the dark at $4{ }^{\circ} \mathrm{C}$ until analysis. Standard additions of cobalt were carried out with Metrohm 765 Dosimats using a programmed dosing procedure (Noble et al., 2008). Concentrations of total dissolved and labile cobalt from USGT11 were measured on land between 1 and 6 weeks after the sampling date, using the same protocol as that employed for USGT10. Analyses were performed on samples preserved in the dark at $4{ }^{\circ} \mathrm{C}$ and in gas impermeable bags with gas-absorbing satchels to ensure that no degradation of the sample occurred during that time.

For total dissolved cobalt analyses, samples were UVirradiated for $1 \mathrm{~h}$ prior to analysis using a Metrohm $705 \mathrm{UV}$ digester to degrade the organic ligands that bind cobalt and allow binding by the added electroactive cobalt ligand, dimethylglyoxime. Samples were analyzed in $8.5 \mathrm{~mL}$ aliquots with the addition of $30 \mu \mathrm{L}$ of recrystallized dimethylglyoxime (DMG, Sigma-Aldrich $0.1 \mathrm{~mol} \mathrm{~L}^{-1}$ in methanol), $1.5 \mathrm{~mL}$ of purified sodium nitrite (Fluka Analytical A.C.S. reagent grade $\geq 99.0 \%, 1.5 \mathrm{~mol} \mathrm{~L}^{-1}$ in Milli-Q water), and $50 \mu \mathrm{L}$ of purified $N$-(2-hydroxyethyl)piperazine$N$-(3-propanesulfonic acid) (EPPS) buffer (Sigma-Aldrich $0.5 \mathrm{~mol} \mathrm{~L}^{-1}$ in Milli-Q water). Reagent purification protocols were modified from those previously published (Saito and Moffett, 2001) in order to accommodate large batches.

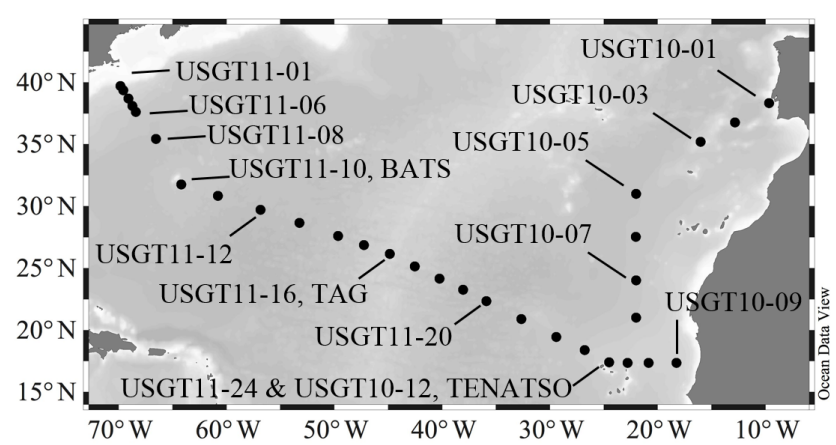

Figure 1. Map of USGT10 and USGT11 expedition tracks.

The DMG was recrystallized after dissolving in an aqueous solution of EDTA to remove any traces of metals. Nitrite solutions were prepared by equilibration overnight on a shaker with Chelex 100 to remove any trace metals. The nitrite solution was then filtered and removed from the Chelex, the Chelex was rinsed with copious amounts of Milli-Q water, and added back to the nitrite solution to equilibrate for a second night on the shaker, followed by filtration into acid-washed HDPE or LDPE bottles. Nitrite was prepared in $500 \mathrm{~mL}$ batches and the batches were blank-checked before shipping to sea. Cobalt concentrations were determined by the standard additions technique, with initial concentrations measured in triplicate followed by four $25 \mathrm{pmol} \mathrm{L}^{-1}$ cobalt additions. A $0.01 \mathrm{mM}$ Co stock solution was prepared by the addition of $14.7 \mu \mathrm{L}$ of a $1000 \mathrm{ppm}$ cobalt standard to a $25 \mathrm{~mL}$ Teflon volumetric flask of Milli-Q water adjusted to $\mathrm{pH}$ 2. Then, $100 \mathrm{~mL}$ batches of $5 \mathrm{nM}$ Co dosing solutions were prepared by the addition of $50 \mu \mathrm{L}$ of the stock solution to a $100 \mathrm{~mL}$ HDPE trace metal cleaned volumetric flask of Milli-Q water that was adjusted to $\mathrm{pH} 3$ using Whatman $\mathrm{pH}$ indicator paper. This dosing solution was added to the Dosimats and used for the standard additions. Final concentration calculations were adjusted for dilution by the nitrite addition.

The analytical blank was determined by analyzing seawater with low trace metal concentration that had been UV-irradiated for $1 \mathrm{~h}$, equilibrated overnight with prepared Chelex 100 resin beads (Bio-Rad), and UV-irradiated a second time to degrade any leached synthetic ligands. This metal-free seawater was kept at room temperature in trace metal cleaned Teflon bottles of 250 and $500 \mathrm{~mL}$ capacity. Blanks for each reagent batch (nitrite, DMG, EPPS) were subtracted from the initial sample concentration. Blank analyses for each reagent batch were made at the beginning and end of use to confirm that the blank remained constant during analyses. The averaged blank for all reagent batches for the entire dataset was $4 \mathrm{pM} \pm 1.2$ with a range of $1.7-6.3 \mathrm{pM}$ ( $n=38$ for individual blank analyses). For a given reagent batch, the standard deviation was smaller, and we report a detection limit ( 3 times the standard deviation of the blank) of $1.8 \mathrm{pM}$, representing the average of the detection limits es- 
timates for reagent batches with at least three blank analyses $(n=6)$.

For labile cobalt analyses, $8.5 \mathrm{~mL}$ of sample was pipetted into acid-washed Teflon vials that were preconditioned with a small aliquot of sample water. Then, $30 \mu \mathrm{L}$ aliquots of DMG were added to each vial and allowed to equilibrate overnight in the dark prior to analysis (Saito et al., 2004). Analyses were then performed as described for total concentrations using the standard addition technique with the addition of the remaining two reagents immediately before analysis. Previously, we determined that natural cobalt is strongly bound to ligands in seawater with a conditional stability constant of $>10^{16.8}$ (Saito et al., 2005). We define labile cobalt (LCo) as the fraction of total dissolved cobalt (dCo) that is exchangeable with the DMG complexing agent, indicating it is either bound to weak organic/inorganic ligands in seawater or present as free Co(II) (Saito et al., 2004, 2005). Where labile cobalt is detectable, the strong cobalt-ligand concentration is defined as the difference between the total dissolved cobalt and the labile cobalt.

Two full electrochemical systems were utilized for analyses, with one dedicated to total cobalt analyses and the other to labile cobalt analyses. GEOTRACES standard seawater and internal standard lab seawater were analyzed periodically to ensure that the two electrodes were intercalibrated and functioning properly. GEOTRACES standard seawater was UV irradiated and neutralized using 1N Optima ammonium hydroxide to increase the $\mathrm{pH}$ to 7.5. An oligotrophic seawater standard internal to our lab was prepared by UV irradiation in $500 \mathrm{~mL}$ batches and stored in trace metal clean Teflon bottles at room temperature. The standard was not acidified at any point, thus avoiding the introduction of error and reagent blank associated with adding acid and base (Saito and Moffett, 2002), and allowing regular re-analysis without any further treatment. These standards were used to troubleshoot when the electrodes malfunctioned and to ensure consistency when operational. These batches were measured to be $53 \pm 3 \mathrm{pM}(n=4), 74 \pm 3$ $(n=9), 71 \pm 3 \mathrm{pM}(n=16)$ and $54 \pm 6 \mathrm{pM}(n=35)$ over the course of the USGT-11 cruise analyses, and $53 \pm 5 \mathrm{pM}$ ( $n=24)$ for the USGT-10 cruise analyses, measured across all reagent batches and both electrode systems. The above results demonstrate that our methodologies are in agreement with current consensus values for UV-irradiated samples, which can be found on the International GEOTRACES Program website (www.geotraces.org), and that we achieve reproducible results on our internal lab standard. On occasion analyses were repeated due to obvious electrode malfunction or to confirm oceanographic consistency of measured values. If the repeated measurement was similar to the initial measured value, the initial value is reported. If the repeated analysis was more oceanographically consistent with adjacent values in the water column, that analysis was used instead.

\subsection{Particle collection and analyses}

Size-fractionated particulate samples were collected by McLane pumps suspended on a Hytrel-jacketed vectran trace metal wire at 22 stations over the two cruises as described in Ohnemus and Lam (2015). Briefly, pumps operated for $4 \mathrm{~h}$, filtering first through $51 \mu \mathrm{m}$ polyester mesh pre-filters (large size fraction, LSF) and then through paired $0.8 \mu \mathrm{m}$ polyethersulfone filters (small size fraction, SSF). Immediately after pump recovery, subsections of the LSF pre-filters were rinsed onto polyethersulfone filters during sample processing in a clean bench and dried in a laminar flow bench at sea. In a land-based clean laboratory, the rinsed LSF and subsections of the top SSF filters were digested in concentrated $\mathrm{H}_{2} \mathrm{SO}_{4} / \mathrm{H}_{2} \mathrm{O}_{2}$ (to digest the filter) and then $4 \mathrm{~N}$ of each of $\mathrm{HF}, \mathrm{HCl}$, and $\mathrm{HNO}_{3}$ acids at $110^{\circ} \mathrm{C}$ to digest all particulate phases, dried, and brought up in $5 \% \mathrm{HNO}_{3}$ for analysis via ICP-MS as described in Ohnemus et al. (2014). Internal drift correction using $10 \mathrm{ppb}$ In and recovery spikes, along with separately digested certified reference materials, showed typically $>93 \%$ recovery for the 17 -element suite, including Co. Particulate Co data presented here are the sum of the LSF and SSF fractions, representing total particulate concentrations $>0.8 \mu \mathrm{m}$. All particulate data and metadata, including blanks and recoveries, are available via the Biological and Chemical Data Management Office (BCO-DMO) repository, dataset \#3871.

\subsection{Intercalibration efforts and data repository}

Our laboratory has participated in the GEOTRACES intercalibration effort using this electrochemical analytical technique. We report our laboratory values for the GEOTRACES and SAFe standard analyses using the above-described electrochemical technique, including those conducted during analysis of the US North Atlantic GEOTRACES Section samples to be SAFe $\mathrm{S} 1=5.4 \pm 2.6(n=9)$, SAFe $\mathrm{D} 2=48.3 \pm 5.5 \quad(n=7), \quad$ GEOTRACES $\quad \mathrm{GS}=31.4 \pm 4.1$ $(n=24)$, GEOTRACES GD $=66.9 \pm 6.2(n=30)$. These results are in good agreement with those from the GEOTRACES intercalibration effort for Co using different methods all using UV oxidation to degrade strong cobalt ligands (information available on the International GEOTRACES Program website: www.geotraces.org).

Comparisons of our CSV data with ICP-MS and flow injection methods at the Bermuda Atlantic Time-Series station, a crossover GEOTRACES station, from this expedition and the Dutch GEOTRACES section GA02, generated values that were similar in the photic zone but higher than other studies in the mesopelagic (Dulaquais et al., 2014b). These observations were reported to the GEOTRACES Intercalibration committee and have delayed incorporation of Atlantic dissolved cobalt data into the Intermediate Data Products. The higher mesopelagic values we observed on fresh and "gas-satchel" preserved samples appear to be real 
based on comparisons with our own unpreserved samples (see Sect. 3.3 below)

All cobalt data generated by this lab and discussed in this paper have been submitted to BCO-DMO and are available at http://www.bco-dmo.org/dataset/3868.

\section{Results and discussion}

\subsection{Oceanographic setting}

The US GEOTRACES North Atlantic expedition track (Fig. 1) was chosen to investigate multiple processes and provinces within the constraints of an approximately zonal section and was completed in two legs, as described in the methods section. From east to west, these provinces included Line W along the coast of New England, a crossover station at BATS, the North Atlantic Subtropical Gyre, the hydrothermal TAG site, a crossover station of TENATSO, the Mauritanian Upwelling, and sampling of MOW.

\subsection{Vertical profiles and sections of total dissolved cobalt and labile cobalt in the North Atlantic Ocean}

The dissolved cobalt data product from USGT10 and USGT11 consisted of 11 and 21 profiles, respectively, totaling 717 total dissolved cobalt and 717 labile cobalt data points that were compiled into ocean sections that were rendered with Ocean Data View (Figs. 2a-b, 3; Schlitzer, 2011). Visual examination of the sections (Fig. 2a-b) and vertical profiles (Fig. 3) showed oceanographically consistent results. The two expeditions included a repeat occupation of a station at TENATSO (Tropical Eastern North Atlantic Time-Series Observatory, USGT10-12 and USGT11-24) where the mean difference between the two profiles was $8 \mathrm{pM}$ overall, and $2.2 \mathrm{pM}$ below $2000 \mathrm{~m}$. These profiles are expected to be similar given the slow timescale of deeper water mass movement relative to the 1-year sampling interval, and this resampling provides a unique opportunity to examine temporal variability on this timescale throughout the water column. Larger differences were observed in the surface and mesopelagic waters, with little to no difference below $2000 \mathrm{~m}$ depth. In surface waters, this difference is explained by the fast movement of surface waters and timescales of the processes affecting cobalt cycling in this highly biologically active part of the water column. In mesopelagic waters (particularly between 1500 and $2000 \mathrm{~m}$ ), differences were observed within a water mass characterized as $>55 \%$ Upper Circumpolar Deepwater (UCPDW) via optimum multi-parameter analysis (OMPA; Jenkins et al., 2015), indicating some temporal variability at these depths even within the relatively short timescale between samplings.

\subsection{Preservation and accuracy of total dissolved cobalt using gas absorption satchels}

The measurement of total dissolved cobalt has always been a challenge due to it having the lowest concentrations of any biologically used metal. During a previous expedition slight differences between at-sea analyses and samples returned to the laboratory were observed within the cobalt maximum inside the OMZ that raised suspicions of a preservation issue for dissolved cobalt (Noble and Saito, unpublished data). Moreover, during GEOTRACES intercalibration efforts, two issues have arisen that also contribute to this difficulty in accurate and reproducible total dissolved cobalt measurements. First, during the initial GEOTRACES intercalibration effort, it was confirmed that UV irradiation was required in all methods to release cobalt from organic ligands that do not degrade or dissociate bound cobalt at low $\mathrm{pH}$. This lack of sensitivity of cobalt ligands to dissociation at low $\mathrm{pH}$ is not surprising: it is well known that the cobalt-containing biomolecule vitamin $\mathrm{B}_{12}$ survives similarly low $\mathrm{pH}$ in the human stomach without dissociation, and that $\mathrm{Co}$ (III) complexes are classic examples of kinetic inertness and stability (Lippard and Berg, 1994). As a result, all samples reported as total dissolved cobalt here and in all of our previous studies have been UVirradiated. More recently, we have become concerned that some intermediate depth samples are prone to loss of dissolved cobalt during storage via redox or other unknown reactions. To document this phenomenon, we present three full profile repeat analyses of USGT10-9 off the coast of Mauritania, analyzed by three preservation protocols: (A) at-sea analyses performed within 2 days of sample collection; (B) in-lab analyses performed after 4 months of storage at $4{ }^{\circ} \mathrm{C}$ in the dark; and (C) in-lab analyses of sample duplicates after 4 months of storage at $4{ }^{\circ} \mathrm{C}$ in the dark, where the bottles were additionally preserved in air-tight, heat-sealed bags with gas-absorbing satchels (Fig. 4). Seawater for the unpreserved, stored analyses (B above) was taken from the same bottles as the at-sea analyses; thus, the sample bottles had a large headspace ( $60 \mathrm{~mL}$ bottles with $\sim 50 \%$ headspace). These analyses and the at-sea analyses showed similar dissolved cobalt concentrations at the top and base of the water column but showed a large deviation at all other depths (Fig. 4). Use of the gas-absorbing satchels to store samples for the same length of time ( $\mathrm{C}$ above) allowed for excellent recovery of dissolved cobalt with a slope close to the $1: 1$ coherence of 0.96 and an $r^{2}$ of 0.99 . Interestingly, almost all of the labile cobalt measured at sea had disappeared in unpreserved samples, indicating the movement of cobalt between chemical forms on the timescale of these experiments (data not shown; Noble and Saito, unpublished data). This has major implications for cobalt speciation on preserved samples in certain biogeochemical regimes, especially the North Atlantic. Interestingly, samples from the Ross Sea did not experience this loss, showing excellent reproducibility on stored, unpreserved samples for both total dissolved and la- 

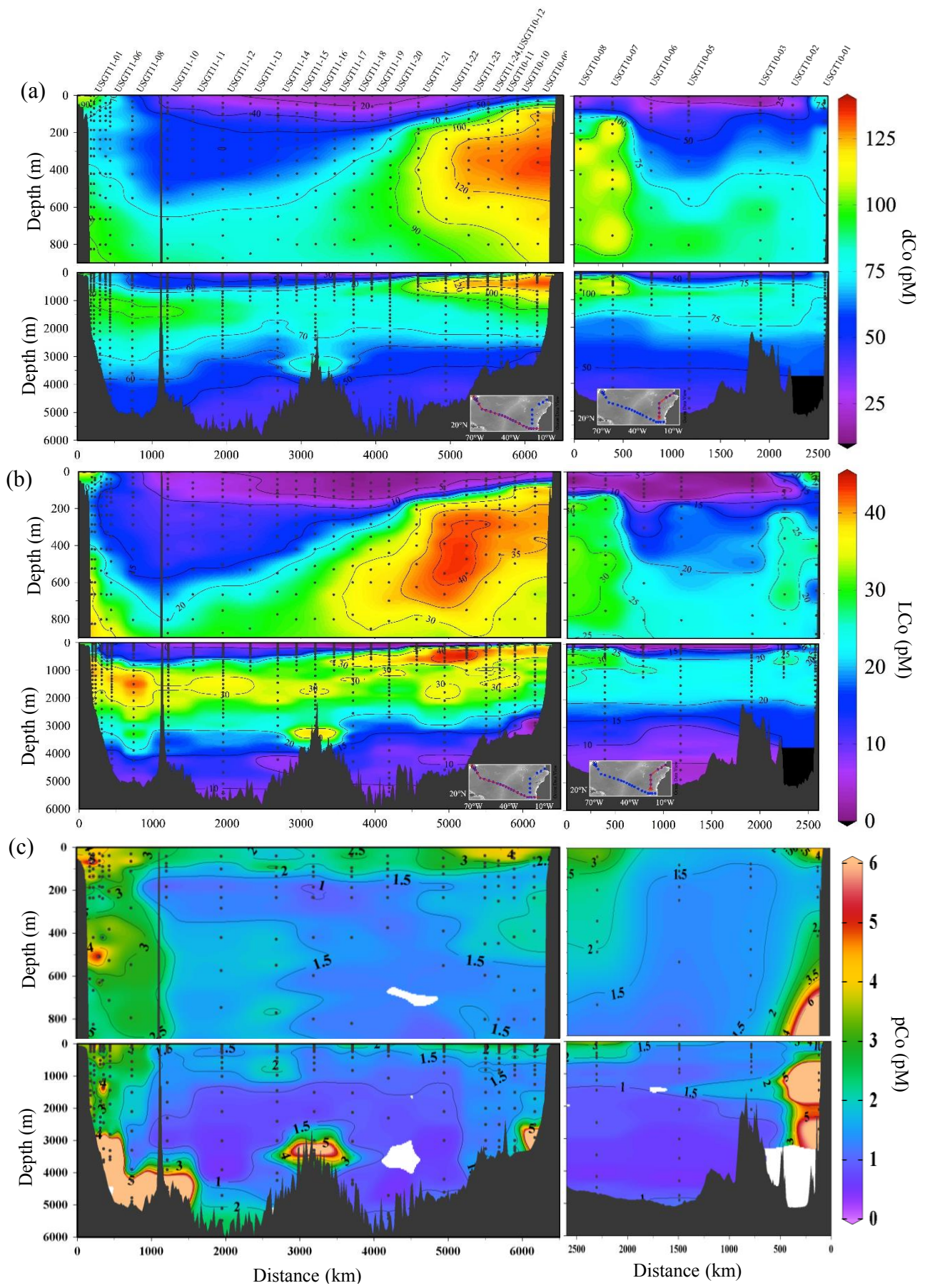

Figure 2. (a) Full depth section of total cobalt, (b) full depth section of labile cobalt, and (c) full depth section of particulate cobalt with the meridional section in the right panels and the zonal section in left panels. These ocean sections were created using Ocean Data View. The dissolved sections were created using "VG" gridding and extrapolated lengths of less than $70 \%$ in either $y$ or $x$ direction for any of the section representations.

bile cobalt after 17 months (Noble and Saito, unpublished data). However, given the successful recovery of total cobalt demonstrated by this new technique in a region prone to low oxygen and heavy dust inputs, we encourage research groups measuring dissolved cobalt to adopt the preservation method used in this study.

A GEOTRACES crossover station was also included at the Bermuda Atlantic Time-Series station (BATS, USGT1110). Data were compared between our lab and two labs that 

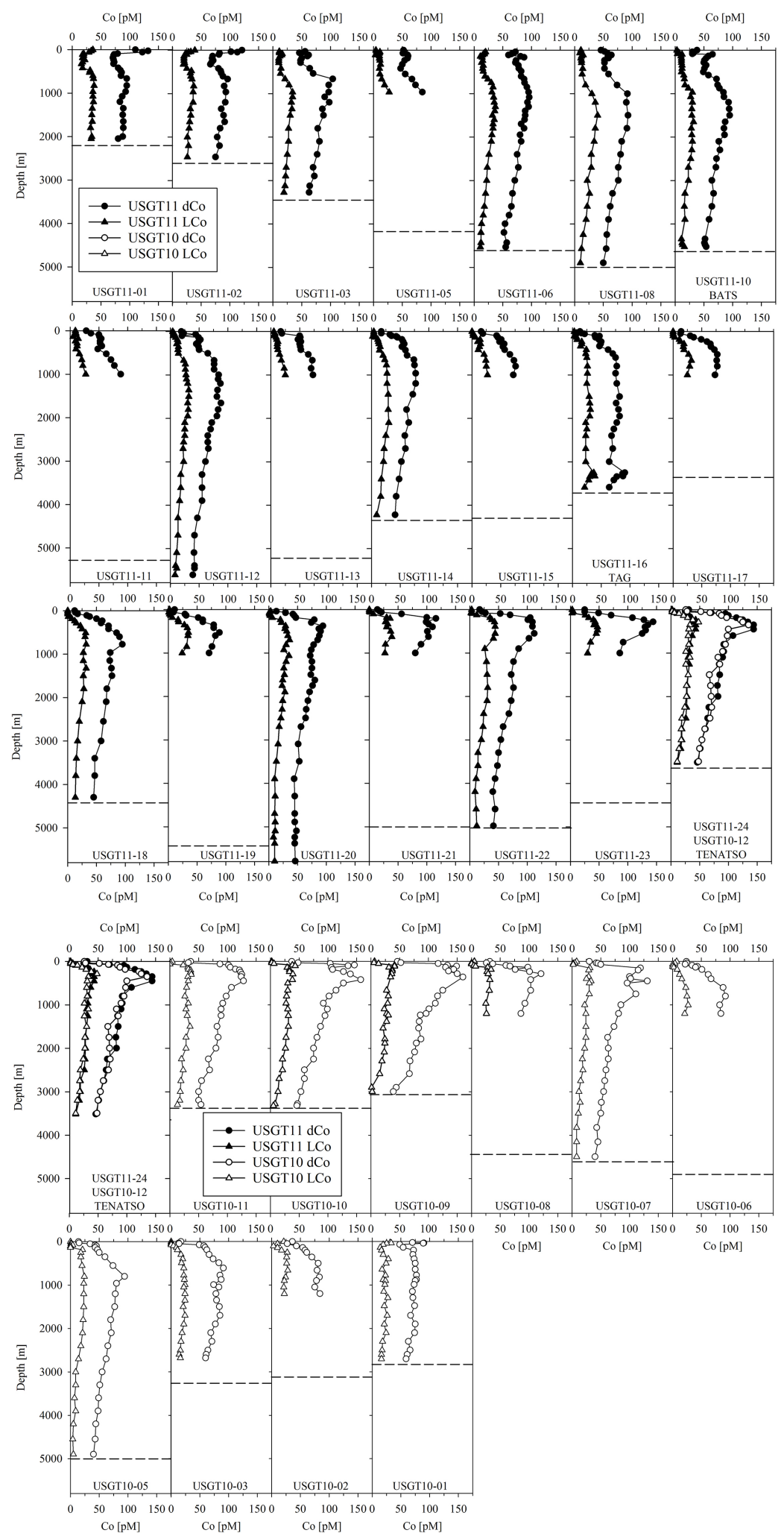

Figure 3. Dissolved profiles of total and labile cobalt for USGT10 and USGT11. Stations of note include USGT11-10 (BATS), USGT11-16 (TAG), USGT10-09 (station closest to the Mauritanian coast), USGT11-1 to USGT11-08 (stations along Line W). 


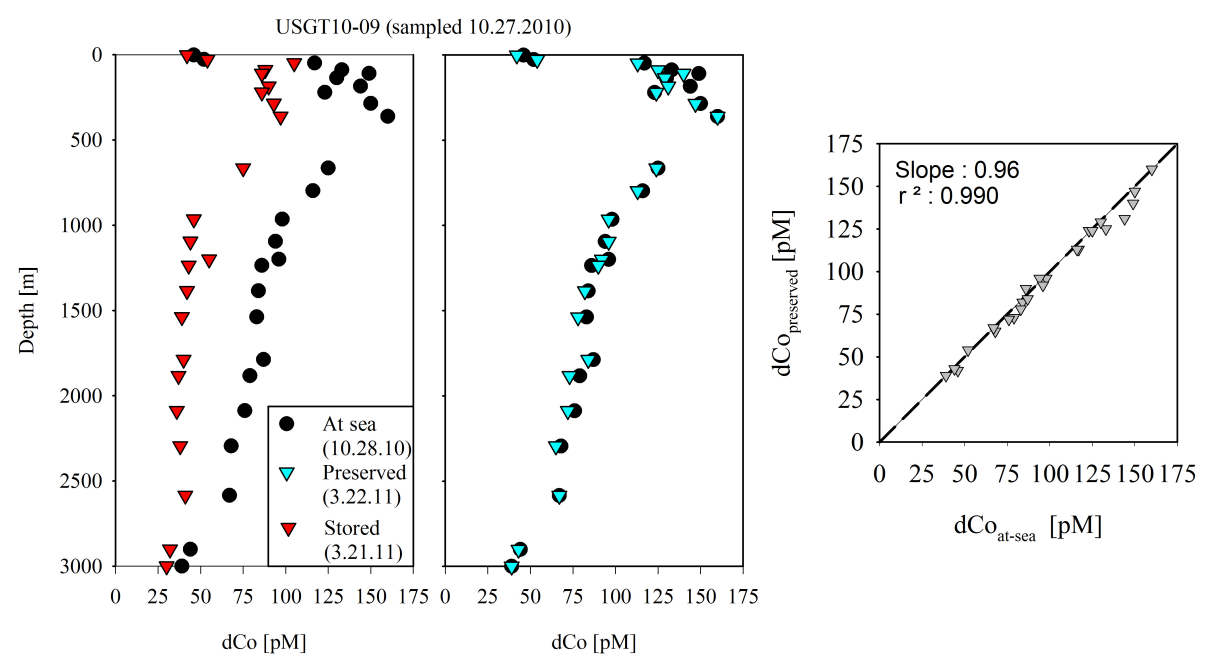

Figure 4. Examination of storage effects and use of gas-absorbing satchels for preservation on a vertical profile from Station USGT109. "Preserved" samples were kept refrigerated in heat-sealed bags with gas-absorbing satchels, while " 4 months" samples were only kept refrigerated. The preserved samples showed excellent recovery after 4 months in cold storage compared with at-sea measurements, while non-preserved samples showed significant loss of dissolved cobalt.

relied on an ICP-MS method (Middag et al., 2015) at this station as well as at a second station in the North Atlantic Subtropical Gyre (USGT11-20). Our laboratory results were found to be consistently higher than those of the other groups (intercomparison data not shown). The largest discrepancies $(\sim 20 \mathrm{pM})$ were observed at intermediate depths associated with the highest labile cobalt concentrations (up to $36 \mathrm{pM})$. Discrepancies were generally smaller in deeper waters (where labile concentrations were often $\leq 10 \mathrm{pM}$ ), and concentrations were often within a few $\mathrm{pM}$ of each other in the upper few hundred meters where labile concentrations were below $10 \mathrm{pM}$ and often below our detection limit. Based on our comparison and preservation experiments in this and other locations, the preservation and storage issue appears to be exacerbated in the North Atlantic and has only a minor influence at some depths in the South Atlantic, Ross Sea, and South Pacific. Hence, we hypothesize that the preservation effects may be related to the extensive dust- and subsequent colloidal loading of the North Atlantic region, and subsequent oxidation of $\mathrm{Co}(\mathrm{II})$ to $\mathrm{Co}(\mathrm{III})$. Ultimately, because comparison of our method with GEOTRACES standards and our internal laboratory standard showed excellent accuracy and reproducibility, we interpret our higher concentrations at intermediate depths to be due to loss of cobalt associated with different preservation techniques used in other methods. Again, this preservation effect appears to be strongest in the North Atlantic, demonstrating only a minor influence in other regions.

\subsection{Major sources of cobalt to the North Atlantic Ocean}

The dissolved cobalt data highlight continental margin sources of cobalt to the intermediate waters of the North Atlantic from both eastern and western margins: a large plume emanated from the African coast along the eastern margin (Sect. 3.4.1), and another large plume was observed along the western margin within Upper Labrador Seawater (ULSW) (Sect. 3.4.2). In addition, regional contributions from coastal inputs (Sect. 3.4.3) were observed and a small, localized plume of cobalt was detected above the Mid-Atlantic Ridge hydrothermal vent site at TAG (Sect. 3.4.5). Atmospheric deposition over the tropical and subtropical North Atlantic is a significant source of a number of metals (e.g., Fe and Mn), but trace cobalt appears to be only a small contribution to the water column inventory (Sect. 3.4.4). Notably, all elevated source signals of total dissolved cobalt were coincident with elevated labile cobalt as well. While the magnitude of the signals differed between the two species, this elevated signal coincidence may indicate sources carried within a water parcel that experiences slower scavenging relative to surrounding waters (e.g., due to low oxygen concentrations) or that the inputs were relatively recent and the maxima were captured in this sampling effort before they were fully scavenged (e.g., close to hydrothermal inputs). The following sections discuss these cobalt sources to the North Atlantic Ocean and compare the relative magnitudes of those sources to those observed in a prior study of the South Atlantic Ocean (the CoFeMUG cruise; Noble et al., 2012). 


\subsubsection{A large plume of cobalt off the Mauritanian coast}

The largest feature of this dataset was the dissolved cobalt plume observed along the eastern margin off of North Africa (Fig. 2). This subsurface plume of dissolved and labile cobalt extended from the Mauritanian coast more than $2000 \mathrm{~km}$ into the basin, based on a conservative definition of the plume of exceeding $100 \mathrm{pM}$ total dissolved cobalt (Fig. 2). Centered around the OMZ, the highest concentrations of dissolved cobalt $(160 \mathrm{pM})$ were detected at $\sim 400 \mathrm{~m}$ depth and were primarily associated with Atlantic Equatorial Waters (AEW). Wind- and circulation-driven upwelling occurs along the Mauritanian coast, leading to higher overall productivity that supports important local fisheries. The subsequent substantial remineralization of organic matter contributes to low-oxygen waters at intermediate depths. This Northwest African/Mauritanian Upwelling region contains the smallest of five major marine OMZs in the oceans, with the others located in the eastern tropical North and South Pacific, the eastern South Atlantic, and the Arabian Sea (Keeling et al., 2010). Previous cobalt studies have shown that the South Atlantic OMZ and the two Pacific OMZs all harbor high concentrations of cobalt (Ahlgren et al., 2014; Hawco et al., 2016; Noble et al., 2012; Saito et al., 2004, 2005). The current study confirms high cobalt concentrations in the North Atlantic OMZ as well, despite this OMZ having higher $\mathrm{O}_{2}$ concentrations and lacking the substantial suboxic and anoxic waters found in other OMZs.

The elevated cobalt observed in the Mauritanian Upwelling is due to a combination of processes: (1) low bottom water oxygen allowing reductively dissolved cobalt to escape from sediments and be transported long distances with minimal removal, and (2) the poorly ventilated shadow zone waters of the OMZ allowing accumulation of cobalt from vertical export of remineralized biogenic and aeolian cobalt. Similar coupling of processes and elevated cobalt were observed in the South Atlantic OMZ on a GEOTRACES-compliant zonal section (GAc01 also known as CoFeMUG; Noble et al., 2012). These two parallel transects afford a unique opportunity to compare contributions from multiple sources that result in similar large-scale dissolved cobalt features. The biogeochemistries of the two regions are somewhat distinct: the North Atlantic is heavily influenced by aeolian input from the Sahara and North America, and upwelling off the coast of Mauritania is $\sim 1.8 \mathrm{~Sv}$ according to ${ }^{3} \mathrm{He}$ measurements (Jenkins et al., 2015). In contrast, the South Atlantic experiences very low overall dust deposition, and upwelling in the Angola Dome and Benguela Upwelling has been estimated to be 2.2 Sv (Frame et al., 2014; Skogen, 1999). In the South Atlantic, the cobalt plume was also centered around the oxygen minimum and was coincident with elevated dissolved manganese and iron (Noble et al., 2012). Similarly, elevated manganese and iron were observed coincident with the North Atlantic OMZ, suggestive of similar processes influencing these trends (Hatta et al., 2015). In the South Atlantic, we suggested that the high OMZ concentrations of these hybrid metals were due to a combination of reductive dissolution, upwelling, advection, and remineralization, and that cobalt in particular appears to be much more slowly scavenged than iron and manganese in these low but not suboxic OMZs (Noble et al., 2012). Reductive dissolution can be a source of cobalt via release of cobalt associated with manganese oxides in sediments along the coast, as we previously suggested for the South Atlantic OMZ system (process \#1 above). This process likely contributes to the plume in the North Atlantic; however, the fraction of the cobalt plume supported by aeolian contributions to the vertical export (process \#2 above) would be expected to be higher. Moreover, oxygen concentrations in the North Atlantic are not as low as those observed in the South Atlantic, but particulate $\mathrm{FeS}_{2}$ has been observed in both the sediments and suspended particulate matter near the Mauritanian Upwelling sampling sites (Lam et al., 2012), suggesting that there may be sufficiently low oxygen concentrations along the shelf to allow the escape of reduced cobalt from the sediments without reprecipitation as oxides. Despite higher mesopelagic oxygen concentrations in the North Atlantic, the dissolved cobalt concentrations were also higher here, likely due to a larger contribution from dust sources in the North Atlantic study area (see Sect. 3.4.4) and/or through less time exposed to scavenging processes within the ocean interior. With the addition of the GA03/3_e section in the North Atlantic, four of the five world's major coastal OMZ regions have now been found to harbor high concentrations of cobalt (Hawco et al., 2016; Noble et al., 2012; Saito et al., 2005). This adds to the growing evidence that OMZs and their accompanying coastal regions are important sources of dissolved cobalt to the oceans. Importantly however, for a basin-scale plume to be observed in the North African OMZ region implies that cobalt plume formation and persistence by slowed scavenging has a higher (low) oxygen threshold than other OMZ processes (e.g., denitrification) that require suboxic or anoxic conditions.

\subsubsection{Advected sedimentary source from Upper Labrador Seawater}

Strong total dissolved cobalt and labile cobalt plumes were also observed in the western Atlantic along Line W (USGT11-01 to the Bermuda Atlantic Time-Series station (BATS, USGT11-10) between 1000-1500 m depth, with no accompanying low-oxygen signal. Water mass analyses using OMPA (Jenkins et al., 2015) constrains the dissolved cobalt feature to be contained within Upper Labrador Sea Water (ULSW). Low silicate concentrations are a differentiating feature of ULSW and can be used to illustrate this by overlaying silicate contours on a western margin section of dissolved cobalt (Fig. 5). Two processes, which are not mutually exclusive, may explain the observed feature: (1) advection of a water mass that contains a higher inventory of cobalt than the surrounding waters and/or (2) coastal input of 


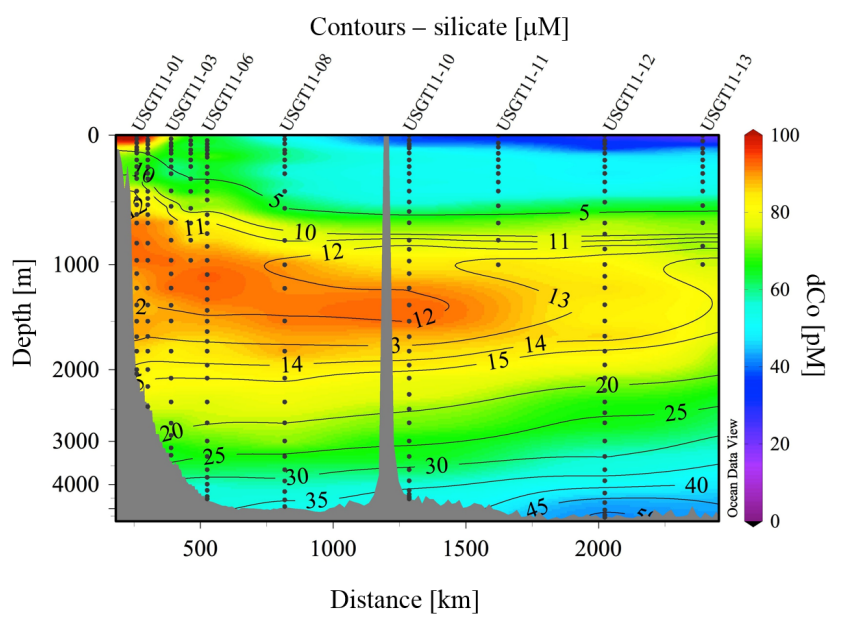

Figure 5. Section of dissolved cobalt and dissolved silicate along the western margin of the North Atlantic (Line W). Upper Labrador Sea Water, identified generally between 700 and $1500 \mathrm{~m}$ depth by OMPA (Jenkins et al., 2015) carries elevated concentrations of cobalt and is depleted in silicate.

cobalt released from shelf sediments as ULSW comes in contact with the coastal shelf and slope during the transit south. Hatta et al. (2015) observed high Fe and Mn on this same GEOTRACES transect within this water mass and invoked release of these metals from sediments into the water column. Previous studies have also invoked continental margin interaction to explain Fe enrichment in Labrador Sea Water at a station further northeast into the Atlantic Basin (Laes et al., 2003), and recent data suggest that Arctic waters may contain very elevated concentrations of cobalt (Saito and Noble, unpublished data; Bundie and Saito, unpublished data) which could provide a source of high cobalt to the locations of ULSW ventilation.

The ULSW cobalt plume appears to be different in composition from that of the eastern margin Mauritanian Upwelling feature. First, the percentage of labile cobalt is higher (35$40 \%$ ) in the western margin ULSW feature than within the eastern margin Mauritanian Upwelling (20-25\%). Higher particulate cobalt is also observed along the western margin (Fig. 2c), and could be related to the higher abundance of both dissolved phases, reflecting increased interaction with this phase via shelf inputs and/or scavenging. The transport of labile cobalt to depths below the photic zone may prevent entrainment of labile cobalt into microbial cycling and its transformation to complexed cobalt. This could explain the speciation differences relative to the eastern basin, where the plume is shallower and labile cobalt is a smaller fraction of total cobalt. Oxygen concentrations are also much higher in ULSW than within the Mauritanian Upwelling plume, further demonstrating that low oxygen is not necessarily critical to sustaining subsurface cobalt plumes. Another possible contribution to the western margin plume could come from remineralized cobalt transported within ULSW from its ori- gin to the north. Cyanobacteria are thought to be major contributors to the oceanic cobalt-ligand inventory and their virtual absence in polar regions has been invoked to explain the often higher fraction of labile cobalt found in the euphotic zone of those regions (Noble et al., 2013; Saito et al., 2010). It appears that the cold polar-sourced Labrador Sea waters may also carry that imprint of higher labile cobalt. These potential contributions are not mutually exclusive: it is likely that both continental shelf inputs and advected remineralization signals from cooler regions contribute to this high cobalt feature of the North American continental shelf and slope environment.

\subsubsection{Coastal sources along the North American margin}

In the upper $40-60 \mathrm{~m}$ along the western margin, surface coastal sources dominate cobalt distributions, and an inverse linear relationship with salinity is observed, indicative of a freshwater end-member source (Fig. 6a). While biological processes often drive relationships of cobalt with phosphate instead of salinity, including at most of the stations sampled during GA03/3_e (see Sect. 3.7), these Co: $\mathrm{PO}_{4}^{3-}$ correlations (Co: $\mathrm{P}$ hereafter) were absent in the Line $\mathrm{W}$ region (Fig. 6b, c). Previous work characterized a similar relationship between salinity and cobalt in the North American margin region (Saito and Moffett, 2002), as well as between salinity and other elements such as copper and nickel (Bruland, 1980). In the current study, the relationship with salinity was similar for labile cobalt, supporting a labile source from the coast. This input of cobalt in conjunction with lower salinities implies potential sources from freshwater input such as rivers or groundwater from the coastal Atlantic region.

\subsubsection{Evaluating aeolian sources to the North Atlantic}

The North Atlantic Ocean is strongly influenced by atmospheric dust deposition, which provides an important source of iron and other metals and can impact regional nitrogen fixation (Moore et al., 2009). The influence of aeolian input from the Sahara increases moving eastward toward the North African margin (Mahowald et al., 2005; Shelley et al., 2012; Ohnemus and Lam, 2015), and the Sahara is an important source of iron and other metals to the northeast Atlantic (Measures et al., 1995, 2008; Shelley et al., 2015). The two legs of the GA03/3_e section both occurred during fall/winter (October-December 2010, 2011), which is typically the low atmospheric deposition period in the western Atlantic (spring is the major period of deposition at BATS (Engelstaedter et al., 2006; Jickells et al., 1990). Dust samples collected during GA03/3_e showed aerosol cobalt loadings associated primarily with lithogenic elements (e.g., $\mathrm{Ti}, \mathrm{Al}$, and $\mathrm{Fe}$ ), and only minor contributions from other aerosol types (Shelley et al., 2015), suggesting that 

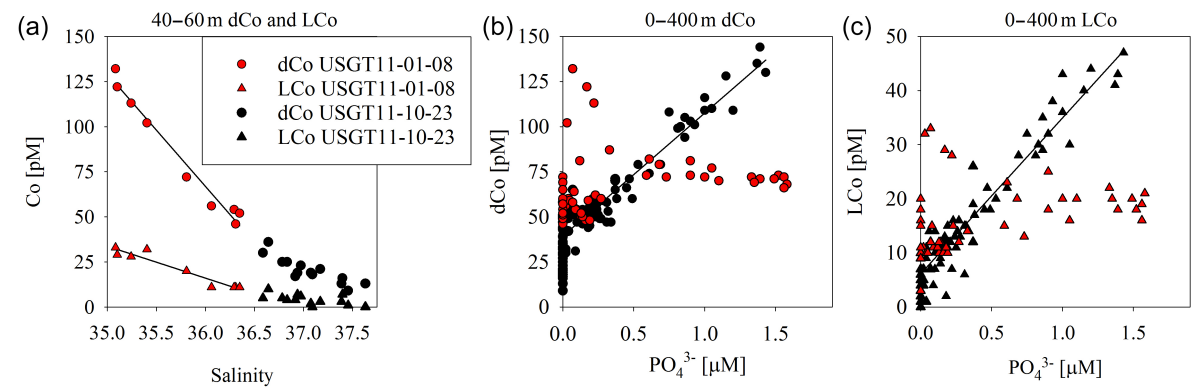

Figure 6. Along Line W, strong relationships between (a) salinity and total cobalt and salinity and labile cobalt were observed in surface waters. Total and labile cobalt show strong correlations with phosphate in the North Atlantic Subtropical Gyre, but this relationship is not observed along Line W (b, c).

desert dust sources were more significant than anthropogenic sources at this time. Lithogenic dust sources are likely a less significant source of cobalt to the North Atlantic Ocean than they are for other metals because cobalt is much less abundant in crustal material (average Co: Fe ratio of $\sim 1: 2600$; Taylor and McLennan, 1985), making it more difficult to resolve aeolian sources from the large coastal cobalt sources described above. In this section, we examine the contribution of dust to dissolved cobalt inventories using cobalt distributions across the basin, correlations with dissolved aluminum in the eastern basin, and estimates of dust flux contributions and relative to upwelling fluxes.

\section{Western North Atlantic}

Unlike iron or aluminum profiles, which show persistent surface maxima on GA03/3_e, dissolved cobalt profiles within the upper water column of the oligotrophic gyre were consistently nutrient-like (Fig. 3), with surface concentrations of total cobalt as low as 9 pM (Fig. 7a-b). Previously published profiles of dissolved cobalt at BATS station demonstrate variability, however, being either nutrient-like or of an atmospheric deposition surface maximum-type depending on the time of year sampled, the seasonality of dust deposition (atmospheric deposition is highest during late spring/ early summer), and mixed layer depth (Saito and Moffett, 2002; Shelley et al., 2012). The nutrient-like profile at BATS during GA03 was consistent with previously published work, since samples were collected during the season of low dust deposition, and the deepening of the mixed layer, which acts to dilute dust-borne cobalt dissolved into shallow mixed layers during summer. Due to this variability, it is important to keep in mind that dust estimates are inherently temporally linked.

Dust deposition near Bermuda appeared to have a small impact on the surface cobalt inventory during GA03. Aerosol cobalt deposition near Bermuda can be estimated as the product of aerosol cobalt concentrations determined from shipboard bulk aerosol sampling $\left(0.15 \mathrm{pmol} \mathrm{m}^{-3}\right.$ for BATS during GA03 and $0.44 \mathrm{pmol} \pm 0.28 \mathrm{~m}^{-3}$ including 12 surrounding deployments to BATS, "BATS region" hereafter; Shel- ley et al., 2015) and a typical dry deposition rate of those aerosols (1000 $\mathrm{m} \mathrm{d}^{-1}$ for BATS station; Duce et al., 1991). This results in a cobalt deposition flux of $0.15 \mathrm{nmol} \mathrm{m}^{-2} \mathrm{~d}^{-1}$ (BATS) and $0.44 \mathrm{nmol} \mathrm{m}^{-2} \mathrm{~d}^{-1}$ (BATS region). The solubility of cobalt in Sahara-derived aerosols collected in the Sargasso Sea has been estimated to be $10 \%$ during periods of high dust deposition (Shelley et al., 2012), similar to longerterm dissolution experiments on lithogenic-rich aerosols collected in the Red Sea (17 $\pm 7 \%$; Mackey et al., 2014). Combining flux and solubility with an observed mixed layer depth of $80 \mathrm{~m}$ during GA03, dust dissolution is estimated to add $\sim 0.06$ (BATS) to $0.17 \mathrm{pM}$ (BATS region) Co per month. This is relatively low compared to the mixed layer inventory of $30 \mathrm{pM}$ at BATS during GA03.

To compliment GA03, which captured the lower range of seasonal dust contribution to the mixed layer inventory, we can consider the higher range: that of seasonally high dust deposition and a stratified mixed layer. During the summer, when dust fluxes are highest, mixed layers can be $<10 \mathrm{~m}$ deep (Steinberg et al., 2001). Shallow mixed layers intensify the assimilation of metals from atmospheric deposition because the fluxes are diluted over a smaller volume (Jickells, 1999). Annual aerosol cobalt fluxes at BATS were calculated to be $944 \mathrm{nmol} \mathrm{Co} \mathrm{m}^{-2}$ year ${ }^{-1}$ using ${ }^{7} \mathrm{Be}$ isotopes and data from July 2011 to June 2012 (Kadko et al., 2015). Considering the extreme case where $100 \%$ of this annual dust deposition is deposited under highly stratified summer conditions (10 m mixed layer depth), with an assumed $10 \%$ Co solubility results in an estimated $9.4 \mathrm{pM}$ increase per year to the mixed layer cobalt inventory. This is a potentially significant contribution compared to the dissolved cobalt observed during GA03 (9-36 pM). Moreover, solubility increases with seawater exposure time (Mackey et al., 2014), episodic dust loadings of high intensity, and/or an increased anthropogenic component with higher solubility (Thuróczy et al., 2010) could also enhance the fractional magnitude of aeolian-sourced dust to the mixed layer. As a result, higher dust deposition and shallower mixed layer depths that occur in the spring and summer at BATS could explain the non- 

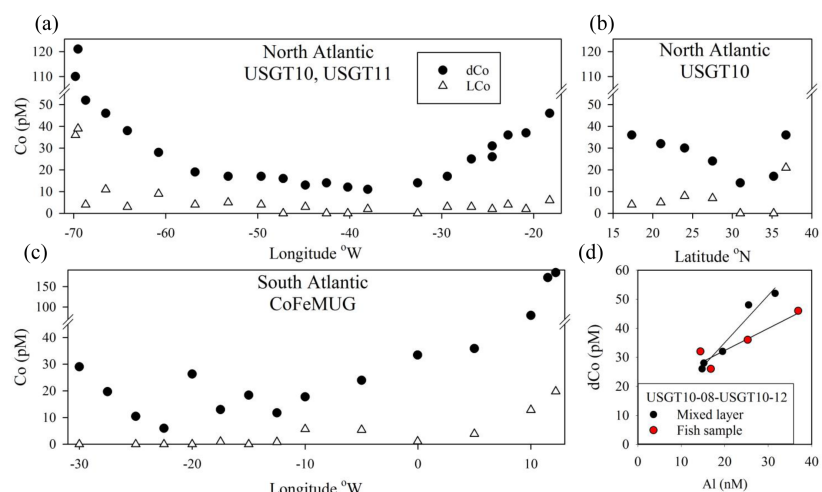

(e)

(f)
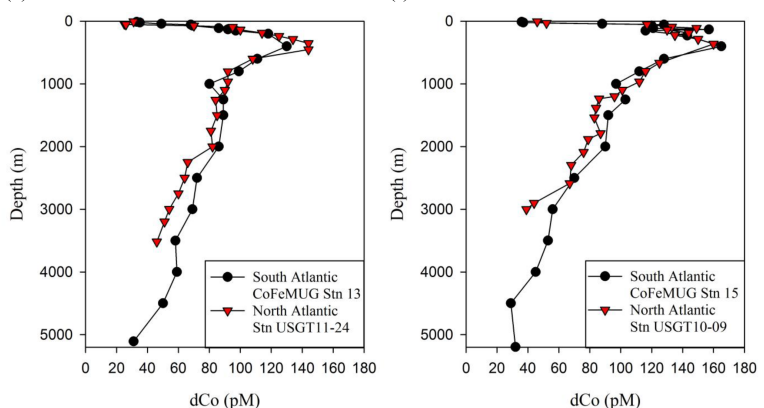

Figure 7. Surface transects of surface fish samples $(\sim 2 \mathrm{~m})$ from $(\mathbf{a}-$ b) the North Atlantic zonal section USGT10 and USGT11, and (c) the shallowest samples $(\sim 5-10 \mathrm{~m})$ from the South Atlantic zonal section CoFeMUG (Noble et al., 2012). (d) Relationships between $\mathrm{dCo}: \mathrm{dAl}$ and correlations for northeast Atlantic stations USGT1008 to USGT10-12. (e-f) Comparison of vertical profiles of dCo between the North and South Atlantic zonal sections near the African coast. Distances of stations to the African coastline were $\sim 530 \mathrm{~km}$ for TENATSO (USGT11-24) and $210 \mathrm{~km}$ from USGT10-09 in the North Atlantic, and $1300 \mathrm{~km}$ for Station 13 and $790 \mathrm{~km}$ for Station 15 from the CoFeMUG Expedition in the South Atlantic.

nutrient-like profiles previously observed (Hansell and Carlson, 2001; Saito and Moffett, 2002; Shelley et al., 2012b).

Taken together, these results imply that the strong seasonal cycle at the BATS station imposes a strong seasonal aeolian influence on the cobalt inventory in the mixed layer. As winter convection homogenizes the upper water column, the spring and summer dust contribution is diluted. When applied to a $100 \mathrm{~m}$ mixed layer instead of a $10 \mathrm{~m}$ mixed layer, the estimated $9.4 \mathrm{pM}$ per year dust flux decreases to $0.9 \mathrm{pM}$ per year, increasing the dissolved inventory by a few percent overall $(2.5-10 \%)$. As dissolved cobalt concentrations increase with depth, winter mixing also provides a considerable flux of cobalt to the surface from deeper waters (Saito and Moffett, 2002), thus decreasing the fractional input from fresh spring and summer dust contribution to the cobalt mixed layer inventory.

\section{Eastern North Atlantic}

Due to proximity to the Sahara, dust sources of cobalt might be expected to more strongly influence cobalt inventories in the eastern Atlantic than inventories at BATS, but sedimentary sources appear to dominate here. Increasing surface cobalt concentrations were observed on GA03/3_e toward the eastern margin (Fig. 7a-b), and surface cobalt concentrations of up to $110 \mathrm{pM}$ (higher than those observed on GA03/3_e) have previously been attributed to dissolution of Saharan aerosols (Bowie et al., 2002). Yet, because both dust deposition and coastal upwelling occur in this region, elevated surface concentrations near the eastern margin cannot be solely attributed to dust deposition. Similarly elevated dissolved cobalt was also observed near the coastal margin in the South Atlantic, which experiences much lower dust inputs than the North Atlantic (Fig. 7c; Noble et al., 2012). Moreover, eastern margin profiles of dissolved cobalt from both the North and South Atlantic expeditions were similar in structure and concentration despite major differences in dust supply and a closer proximity of North Atlantic margin profiles to the coast than those in the South Atlantic (Fig. 7ef; see caption).

Upwelling appears to be the major source of cobalt to the euphotic zone in the northeast Atlantic, and can be demonstrated by considering both the aeolian and upwelling fluxes to the eastern margin mixed layer. Similar to the estimates at BATS, the contribution of aerosol dust to dissolved cobalt in the eastern North Atlantic can be estimated from the aerosol cobalt concentrations measured on GA03/3_e, combined with standard deposition velocities and relative solubility already discussed. North African dominated aerosols along USGT10 averaged $17 \mathrm{pmol} \mathrm{Co} \mathrm{m}^{-3}$ (Shelley et al., 2015), over 100-fold higher than that measured at BATS $\left(0.15 \mathrm{pmol} \mathrm{Co} \mathrm{m}^{3-}\right.$, discussed above). This implies a soluble cobalt flux on the order of $1.7 \mathrm{nmol} \mathrm{m}^{-2} \mathrm{~d}^{-1}$ to the mixed layer between USGT10-08 and USGT10-12. Upwelling contributes to cobalt inventories in the mixed layer as well and Jenkins et al. (2015) estimated upwelling rates during GA03/3_e to be $5 \mathrm{~m} \mathrm{~d}^{-1}$ (Jenkins et al., 2015). A dissolved cobalt concentration at the base of the mixed layer of $\sim 50 \mathrm{pM}$ implies an upward flux $250 \mathrm{nmol} \mathrm{m}^{-2} \mathrm{~d}^{-1}$. The soluble cobalt flux from dust during GA03/3_e $\left(1.7 \mathrm{nmol} \mathrm{m}^{-2} \mathrm{~d}^{-1}\right)$ is only $\sim 1 \%$ of this upwelling flux $\left(250 \mathrm{nmol} \mathrm{m}^{-2} \mathrm{~d}^{-1}\right)$. It is possible, though, that a portion of the upwelling flux could be due to less-recent dust deposition and more gradual dissolution. Ohnemus and Lam (2015) observed a strong lithogenic signal in particles within the mesopelagic of this region that they attributed to dust fluxes through sinking dust material, and gradual dissolution of cobalt from sinking lithogenic particles has also been observed experimentally (Mackey et al., 2014). This suggests that while subsurface fluxes primarily sustain the mixed layer cobalt inventory, there may be a component of 
this subsurface flux that is ultimately attributable to dust supply.

Tracers of dust input can help distinguish external sources of cobalt from dust, and comparisons between $\mathrm{dCo}: \mathrm{dAl}$ in the North and South Atlantic surface waters show significant differences. Despite the dominance of upwelling fluxes of cobalt in the eastern North Atlantic, dissolved cobalt was observed to correlate with dissolved aluminum, a tracer of lithogenic dust deposition in surface waters between USGT10-08 and USGT10-12 $\left(r^{2}=0.96\right.$, Fig. 7d, dissolved aluminum data from Measures et al., 2015). The slope of this relationship (1-2 mmol dCo: $\mathrm{mol} \mathrm{dAl}$ ) was much steeper than that expected from their relative abundance in aerosols on GA03/3_e ( $0.16 \mathrm{mmol} \mathrm{Co}: \mathrm{moldAl})$, despite their similar solubilities in North African aerosols (5-15\%; Buck et al., 2010; Mackey et al., 2015; Shelley et al., 2015). Perhaps this deviation was related to artifacts in solubility measurements or differential biological processing: productivity is quite high in the Mauritanian Upwelling region and this $\mathrm{dCo}: \mathrm{dAl}$ relationship in surface waters may reflect rapid uptake of both elements (biological uptake for cobalt and scavenging for aluminum) and subsequent release by remineralization. This influence was evident in depletion of both elements in the upper water column (Figs. 2, 3), and the lower abundance of $\mathrm{dAl}$ in the eastern (near Africa) portion of the GA03/3_e transect relative to the west (near BATS; Measures et al., 2015). This $\mathrm{dCo}: \mathrm{dAl}$ relationship was not observed in surface waters of the Benguela Upwelling in the South Atlantic, where dust input was much lower, but upwelling was also strong (Noble et al., 2012). This coupling of dCo and $\mathrm{dAl}$ in the North Atlantic implies both an influence of dust and a complex interaction with the high productivity of the upwelling region.

As demonstrated above, high cobalt concentrations in the underlying OMZ cause upwelling fluxes of cobalt to be much larger than dust dissolution. Since cobalt in the surface ocean is acquired by phytoplankton, exported to depth and then remineralized, it is possible that atmospheric deposition of cobalt contributes to the OMZ cobalt plume indirectly, thereby returning to the surface ocean when these waters are upwelled. Tritium/helium ages of these water masses have ventilation ages on the order of several decades (Jenkins et al., 2015), allowing cobalt originally delivered to the surface ocean to accumulate in the OMZ after it is remineralized. Continued dissolution of cobalt from dusts that have already sunk below the euphotic zone may provide an additional cobalt source to these depths (Mackey et al., 2014). Therefore, despite instantaneous dust fluxes that are dwarfed by ocean mixing, storage of dust-derived cobalt in the mesopelagic ocean may cause dust-borne cobalt to be significant in sustaining the cobalt inventory in the North Atlantic Ocean on longer timescales.
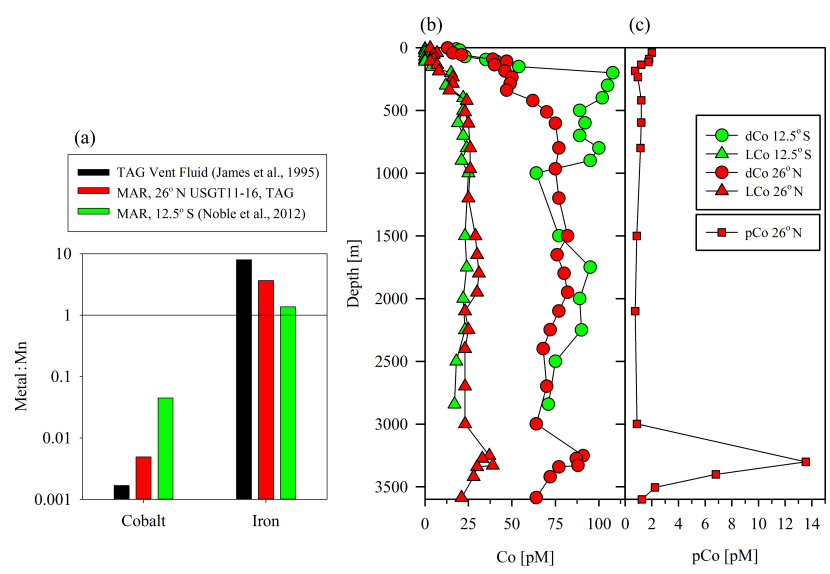

Figure 8. (a) Manganese-normalized cobalt and iron concentrations in hydrothermal fluid and above the Mid-Atlantic Ridge. Hydrothermally leached crust may reflect ratios of reducible metals that are similar to that found in crustal material. Normalized cobalt and iron values are consistent with what might be expected by dilution of hydrothermal fluids measured at TAG. This is consistent with dissolved data from above the Mid-Atlantic Ridge at $9^{\circ} \mathrm{S}$ as well. (b) Profiles of dissolved total and labile cobalt above the TAG hydrothermal vent and above the Mid-Atlantic Ridge at $9^{\circ} \mathrm{S}$. A slight maximum in total and labile cobalt suggests that hydrothermally released cobalt at TAG is primarily labile and that the vent may provide a small, local source of cobalt. (c) Particulate cobalt profile at TAG.

\subsubsection{Hydrothermal source of cobalt to the deep North Atlantic}

The influence of hydrothermalism on dissolved and particulate cobalt was clearly detectable in near-field Mid-Atlantic Ridge samples, but unlike iron and manganese, these effects did not persist appreciably beyond the ridge station. In the North Atlantic deep water concentrations of cobalt were low (39-55 pM), likely due to scavenging and the intrusion of deep water masses with a smaller cobalt inventory. Samples taken at the TAG hydrothermal field (USGT11-16), however, showed a subtle increase in cobalt concentration relative to the surrounding waters (Figs. 2, 3, 8). Five samples were taken within the plume between 3200 and $3500 \mathrm{~m}$ depth above the well-studied TAG hydrothermal vent site (Fig. 8b). A maximum in both dissolved and labile cobalt was observed, constituting a $\sim 37 \%$ increase over adjacent depths within the vertical profile for a $\sim 25 \mathrm{pM}$ hydrothermal signal over background of which $\sim 16 \mathrm{pM}$ is labile cobalt. The presence of labile cobalt in the hydrothermal plume implies that cobalt was released primarily in a labile form and that the vent may act as a local but small source of cobalt to surrounding waters.

Cobalt concentrations in hydrothermal vents have previously been studied at TAG and can be taken as potential mixing end members (James et al., 1995; Swanner et al., 2014). Suspended particulate cobalt exhibited a dramatic maximum 
in the hydrothermal plume (12.5 pM pCo, Fig. 8c), a 20-fold increase over the background concentrations $(\sim 0.6 \mathrm{pM} \mathrm{pCo})$ as observed in the particulate cobalt ocean section (Fig. 2c). The differences between the dissolved cobalt and dissolved iron and manganese within the hydrothermal maximum were staggering: iron concentrations reported in the plume are almost 4 orders of magnitude higher than that of cobalt, and manganese concentrations are 3 orders of magnitude higher (Hatta et al., 2015). These iron and manganese features were observed at adjacent stations as well, while the cobalt feature was confined to the near-ridge region at USGT11-16. These large differences should be considered in light of their respective background concentrations away from the vents: Cobalt concentrations are approximately 1 order of magnitude less than that of iron, and approximately 4-fold less than that of manganese. Thus, even taking the higher relative concentrations of iron and manganese into account, the near-field net hydrothermal source difference between metals was major. Dramatically high concentrations of particulate iron oxyhydroxides were also observed at the vent site $(\sim 50 \mathrm{nM} \mathrm{pFe}$; Ohnemus and Lam, 2015), which likely controlled the overall modest increase in dissolved cobalt distributions by dominating cobalt scavenging. Evidence for localized scavenging at the vents was also observed in negative $\mathrm{dCo}: \mathrm{P}$ relationships in samples closest to the TAG vent site (see companion paper, Saito et al., 2017, their Figs. 6 and 7, bottom depths of station 1116). Interestingly, no similarly dramatic increase in pMn was observed, implying the near-field Co scavenging was related to iron oxide precipitation rather than $\mathrm{Mn}$ oxidizing bacterial activity (Ohnemus and Lam, 2015).

Cobalt comprises a much smaller fraction of crustal material than these other metals, so hydrothermally leached crust may be expected to reflect similar ratios to that found in crustal material. When dissolved cobalt and iron reported above are normalized to manganese, the relative values are consistent with the dilution of hydrothermal fluids measured at Rainbow, one of the vents located at TAG (Fig. 8a; Hatta et al., 2015; James et al., 1995). This observation is also consistent with the relative concentrations detected just above the Mid-Atlantic Ridge in the South Atlantic, where no notable cobalt feature was found amidst pronounced $\mathrm{Mn}$ and $\mathrm{Fe}$ plumes (Fig. 8; Noble et al., 2012; Saito et al., 2013), likely due to the dilution of the hydrothermal cobalt contributions to below the North Atlantic Deepwater background inventory. The observation of the hydrothermal cobalt signal in the North Atlantic zonal transect but not the South Atlantic zonal transect was likely a result of the targeted and close sampling of a known hydrothermal field, while the South Atlantic transect accidentally observed a large hydrothermal plume without prior knowledge of any nearby potential hydrothermal field sources to the sampling locations. Circulation patterns at vent sites may also be characterized by circulation patterns that are constrained by the bathymetry of the spreading system, creating a local swirling effect that may allow particle reactive metals to precipitate with less lateral advection (German et al., 1991).

\subsubsection{No discernible source of cobalt from Mediterranean Outflow Water}

Off the coast of Portugal near the opening to the Mediterranean Sea, Mediterranean Outflow Water (MOW) was sampled at stations USGT10-01 to USGT10-08 within the meridional section at a depth range of $\sim 1000-1500 \mathrm{~m}$ (Jenkins et al., 2015) (Figs. 2 and 3). There was no discernible MOW source of elevated cobalt to other Atlantic water masses, similar to a lack of dissolved iron in MOW observed on this transect (Hatta et al., 2015). Previous studies have observed slightly elevated concentrations of these metals (Bowie et al., 2002; Morley et al., 1997), and high aluminum concentrations within the profiles at stations USGT10-01 to USGT1008 helped confirm the presence of MOW (Measures et al., 2015). This section also revealed slight increases in $\mathrm{Pb}$ concentration coincident with MOW (Noble et al., 2015). Significantly elevated lithogenic particle loads were also identified in these samples (Ohnemus and Lam, 2015), though, suggesting perhaps that any labile particulate cobalt may have already been released or otherwise removed from these particles. Cobalt concentrations were quite uniform within MOW during this expedition, which may be reflective of the short residence time of the Mediterranean Sea of $\sim 100$ years (Lacombe et al., 1981).

\subsection{Variable influence of deep margin nepheloid layers}

The role of the sediment-water interface and sediment resuspension in nepheloid layers has long been thought to influence the distributions of trace metals, yet few expeditions have sampled these deep regions, and none we are aware of for dissolved cobalt. The North Atlantic zonal GEOTRACES section provided a useful opportunity to examine these potential interactions, and the differences in cobalt concentration in deep waters along the margins are more complex than dissolution and release near the bottom: the processes that stir up and create nepheloid layers, which provide increased surface areas for scavenging removal of cobalt, can also promote benthic release of dissolved cobalt. Here we observed a variable influence of nepheloid layers on the distributions of dissolved cobalt that may be related to particle density and composition.

Along the western margin of the North Atlantic transect, a pronounced nepheloid layer was sampled at USGT11-06 and USGT11-08 (characterized by suspended particulate mass maxima (SPM) of $763 \mu \mathrm{g} \mathrm{L}^{-1}$ at USGT11-08; USGT1106 was not sampled for particles), and a less dramatic but thicker nepheloid layer at USGT11-10 (SPM maximum of $40 \mu \mathrm{g} \mathrm{L}^{-1}$; Lam et al., 2015, Fig. 9a-c). This thick nepheloid layer extended several hundreds of meters into the water column but produced a gradual and small decrease in transmit- 
tance voltage. Transmittance voltage is not the best indicator of suspended particulate mass due to differential sensitivity to particles of different composition, but it does give an indication of the presence of these features, which have been confirmed and characterized more quantitatively by chemical determinations of SPM (Lam et al., 2015).

At USGT11-06 ( 4500-4900 m), the bottom two depths showed slightly $(\sim 3 \mathrm{pM})$ elevated total dissolved cobalt relative to the waters above. This could be due to contributions from different water masses that have experienced differing degrees of scavenging over time and/or release of cobalt from the nepheloid layer sampled therein. At USGT11-10, slight increases in total $(8 \mathrm{pM})$ and labile $(5 \mathrm{pM})$ cobalt concentration approaching the deepest sample are also suggestive of resuspended and redissolved particulate cobalt. This slight increase in dissolved cobalt concentration was accompanied by a strong increase in suspended particulate cobalt (Fig. 9c). At USGT11-08, however, where the highest deepwater concentration of suspended particulate cobalt was observed, there was no significant increase or decrease in dissolved total or labile cobalt. No major differences were observed among the water masses occupying the bottom depths between USGT11-06, USGT11-08, and USGT11-10. These observations suggest a balancing act between the source function of resuspension (benthic release of $\mathrm{dCo}$ ) and the sink function of the nepheloid layer itself (increased surface area for scavenging, i.e., SPM). It is possible that at USGT11-10, the SPM maximum $\left(40 \mu \mathrm{L} \mathrm{L}^{-1}\right)$ was not high enough to overcome the source from benthic release. At USGT11-08; however, the much higher SPM $\left(763 \mu \mathrm{g} \mathrm{L}{ }^{-1}\right)$ may have sufficiently scavenged any cobalt from benthic sources. The lithogenic particles that dominate these nepheloid layers are not particularly good scavengers (Lam et al., 2015), and composition likely plays a role in the differences observed between the western and eastern margins.

Along the eastern margin, USGT10-09 also sampled a notable, though smaller, nepheloid layer (SPM max of $44 \mu \mathrm{g} \mathrm{L}^{-1}$, Lam et al., 2015), but here a distinct minimum was observed in total dissolved and labile cobalt, coincident with a significant maximum in suspended particulate cobalt (Fig. 9f). This nepheloid layer, unlike the western margin nepheloid layer, contained particulate manganese and iron oxyhydroxides, which are likely much more efficient scavengers of cobalt than lithogenic particles (Lam et al., 2015). Labile cobalt was undetectable in the deepest sample, suggesting that all cobalt was tightly complexed or that the labile fraction had been scavenged away. This decrease in labile cobalt was also observed at stations UGST10-10 and USGT10-11, which had smaller nepheloid layers and lower concentrations of resuspended particulate cobalt (Fig. 9d, e). It is interesting to see this contrast between a western margin slight enrichment of dissolved cobalt (USGT11-10) compared to an eastern margin strong depletion of dissolved cobalt (USGT10-09) when both sets of profiles display notable nepheloid layers and elevated particulate cobalt. It high- lights the chemical diversity of the dissolved and particulate phase interactions and suggests that future particle composition characterization and process studies along these margins could provide mechanistic explanations for the ability of particles to act as sources or sinks of cobalt to the dissolved pool.

\subsection{Inverse relationship with oxygen and implications for deoxygenation}

In intermediate depths, and particularly within the eastern margin cobalt plume, cobalt and dissolved oxygen showed a significant inverse relationship (Fig. 10). As mentioned in Sect. 3.4.1, elevated concentrations here are likely driven by a combination of a sedimentary source involving reductive dissolution and advection, as well as remineralization of sinking biological material. Both of these processes are linked to oxygen in an inverse fashion and are the likely explanation for this linear relationship. The low $\mathrm{O}_{2}$ concentrations also allow for the persistence of high dissolved cobalt through slowed oxidation into manganese oxide particles (Moffett and Ho, 1996). In our previous study of the South Atlantic, we discussed the potential for trace metal ocean inventories to increase as a result of ocean deoxygenation (Noble et al., 2012), based on observations compiled by Stramma et al. (2008) of deoxygenation within the major OMZs across the world oceans over the last 50 years. In our South Atlantic work, we made a back-of-the-envelope calculation of the influence of increasing ocean deoxygenation and potential for increasing sedimentary release of cobalt assuming a linear relationship in concert with deoxygenation rates determined by Stramma et al. (2008). While this assumption that the linear inverse $\mathrm{dCo}: \mathrm{O}_{2}$ relationship would be constant moving forward in time is simplistic since its mechanistic basis remains unknown, it provides a useful first approximation of potential increases in cobalt ocean inventories.

Here, we apply the same approach to the North Atlantic OMZ to estimate the potential increase in cobalt inventory in the upper $1000 \mathrm{~m}$ of the North Atlantic that may be attributed to deoxygenation. Within the low-oxygen region of the North Atlantic, between 300 and $800 \mathrm{~m}$ depth, cobalt and $\mathrm{O}_{2}$ display an inverse relationship (Fig. 10d) with a slope of

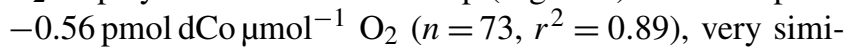
lar to our findings in the South Atlantic $\left(-0.56, r^{2}=0.73\right.$; Noble et al., 2012). This suggests that a similar chemistry governs the relationship with respect to scavenging, which could be related to the oxygen needs of manganese oxidation and co-oxidation that influence removal of the cobalt from the water column. Stramma et al. (2008) estimated an ocean deoxygenation rate for the North Atlantic OMZ of $-0.34 \mu \mathrm{mol} \mathrm{O} \mathrm{kg}^{-1} \mathrm{yr}^{-1}$ over the past 50 years. Together, these relationships can be used to estimate potential future increases in cobalt concentrations within the OMZ. An upper $1000 \mathrm{~m}$ cobalt inventory from USGT11-10 (BATS) across the basin to the most coastal station at USGT10-09 was estimated by summing the estimated dissolved cobalt within 


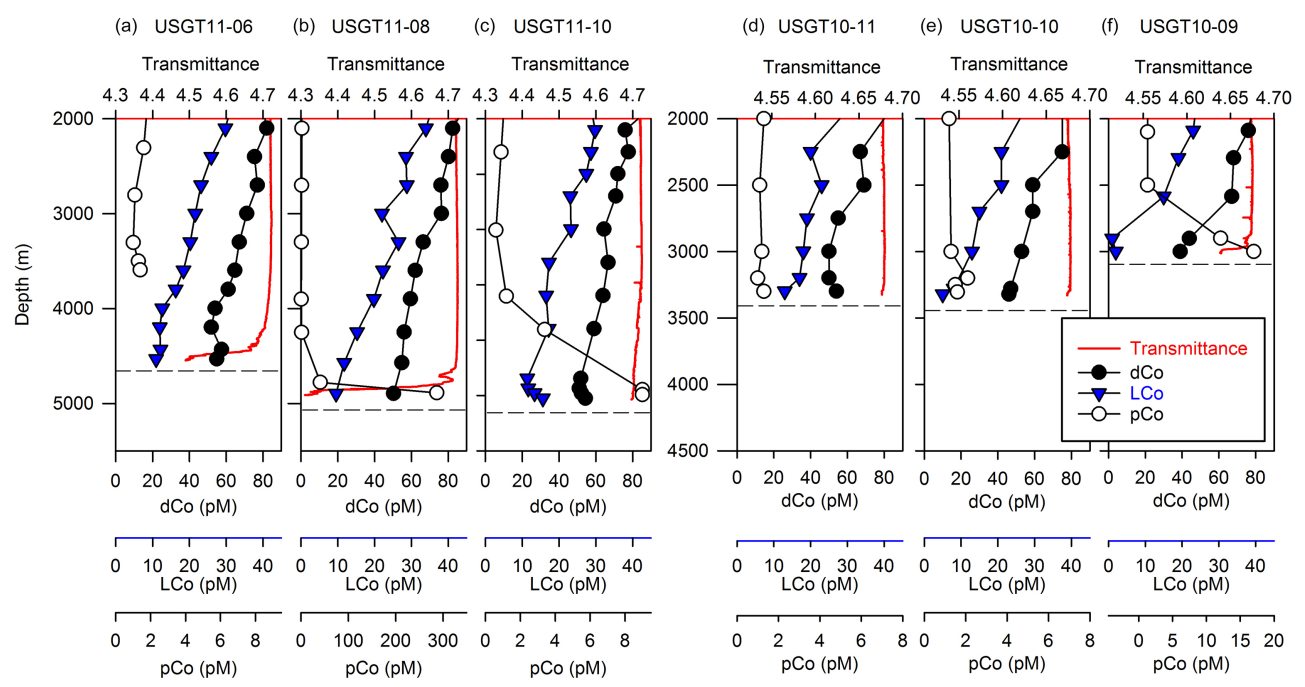

Figure 9. Along the margins, nepheloid layers have differing effects on the dissolved cobalt concentration and composition. Thick and large nepheloid layers along the western margin $(\mathbf{a}, \mathbf{b}, \mathbf{c})$ appear to have small or insignificant effects on the dissolved and labile cobalt profiles, while a moderate nepheloid layer along the eastern margin at USGT10-09 (f) appears to have a strong scavenging effect on the dissolved cobalt. Labile cobalt in the deepest samples here were below the detection limit. The differences in the effect of nepheloid layers on the dissolved cobalt concentrations demonstrates chemical diversity in the dissolved-particulate phase interactions.

each of many trapezoid-shaped water parcels, utilizing each depth and the distance between adjacent stations to interpolate cobalt concentrations between stations and between samples. We then estimated the potential impact of deoxygenation rates on the cobalt inventory within the OMZ, and that subsequent impact on the upper $1000 \mathrm{~m}$ inventory as a whole by using the $\mathrm{dCo}: \mathrm{O}_{2}$ relationship and North Atlantic deoxygenation rate described above. The upper $1000 \mathrm{~m}$ is utilized because of the low- $\mathrm{O}_{2}$ waters found in the $250-850 \mathrm{~m}$ depth range, although this calculation could be easily modified for other depth ranges. Extrapolating forward 100 years, using this simple calculation we estimate that the cobalt inventory in the upper $1000 \mathrm{~m}$ of the North Atlantic could increase by $20 \%$ in the next 100 years. These large potential changes in upper ocean inventories may have implications for the ecological balance within this basin. For example, cobalt is capable of co-limiting the growth of some phytoplankton (Saito et al., 2005), and it is required by the marine cyanobacteria Prochlorococcus and Synechococcus (Sunda and Huntsman, 1995; Saito et al., 2002). A $20 \%$ increase is also 2fold higher than the $\sim 10 \%$ estimated for the South Atlantic, which is largely due to the 2-fold higher rate of deoxygenation reported for the North Atlantic OMZ $\left(-0.34 \mu \mathrm{mol} \mathrm{O} \mathrm{O}_{2}\right.$ $\left.\mathrm{kg}^{-1} \mathrm{yr}^{-1}\right)$ relative to the South Atlantic OMZ $(-0.17 \mu \mathrm{mol}$ $\mathrm{O}_{2} \mathrm{~kg}^{-1} \mathrm{yr}^{-1}$; Stramma et al., 2008). These results imply a need to consider the influence of changing oceanic oxygen on the biogeochemistries of metals and their influence on marine ecology.

\subsection{Relationships of dissolved and labile cobalt with soluble reactive phosphate in the upper Atlantic Ocean}

Dissolved cobalt distributions in the oceanic upper water column are influenced by biological processes such as uptake and remineralization (Noble et al., 2008). The nutrient stoichiometry of the aggregate microbial ecosystem can be inferred using a similar approach to that originally used by Alfred Redfield for dissolved and particulate nitrogen and phosphate (Redfield et al., 1963), where linear relationships between dissolved cobalt and soluble reactive phosphate can be interpreted as time-integrated signals of the extent of cobalt utilization by the resident phytoplankton community and their subsequent remineralization from the biological particulate phase. The aggregate slope of this correlation is termed the "ecological stoichiometry" for their inferred biological usage (Sterner and Elser, 2002). This aggregate slope includes contributions from all sources and sinks of cobalt. We assume that dissolution from dust releases labile cobalt, and we know that strong cobalt-binding ligands are biogenic, but the relative contributions of labile and complexed cobalt from biological uptake and remineralization are still largely unknown. Studying the trends in cobalt-to-phosphate relationships can then be used as tool to gain information about these contributions.

An emerging distinguishing feature of cobalt relative to other macro- ( $\mathrm{N}$ and $\mathrm{P})$ and micronutrients $(\mathrm{Zn}$ and $\mathrm{Cd})$ is a much larger range in stoichiometries when different oceanic regions are compared (Noble et al., 2008, 2012; Saito et al., 2010; Baars and Croot, 2015; Bown et al., 2011; Sunda and 
(a)

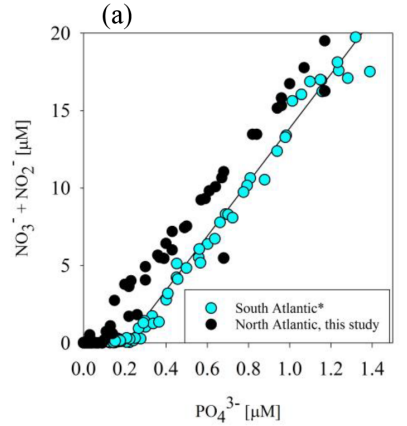

(c)

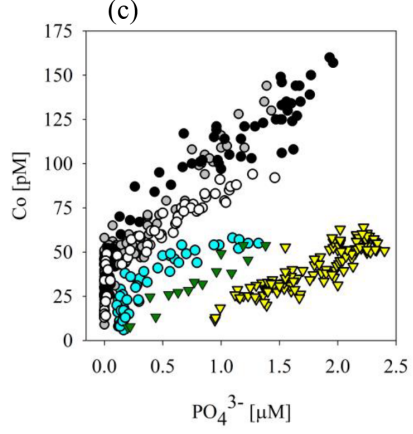

(d)

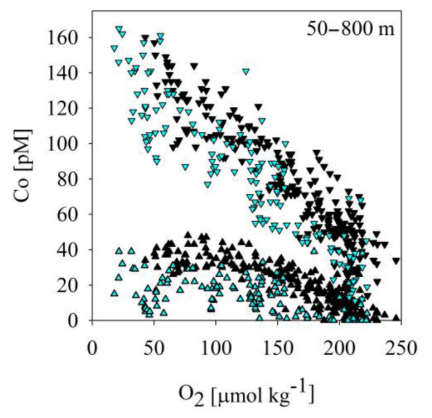

(b)

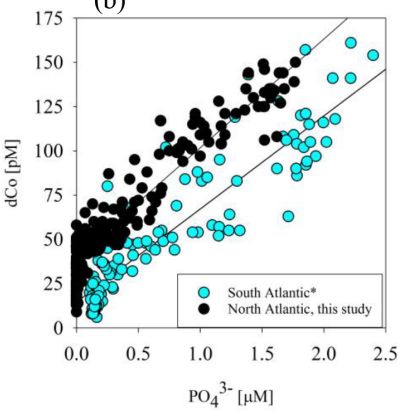

- USGT11-10 to USGT11-23, 0-400 m USGT10-07 to USGT10-12, USGT11-24, 0-350 m USGT10-01 to USGT10-06, 0-900 m

- CoFeMUG, S. Atlantic Subtropical Gyre Stn. 1-7, 0-200 m Subtropical Gyre Stn. 1-7, 0-200 m $\begin{array}{ll}\nabla & \text { N.E. Pacific (T5, T6, T8), 0-150 m } \\ \nabla & \text { Ross Sea 0-500 m }\end{array}$

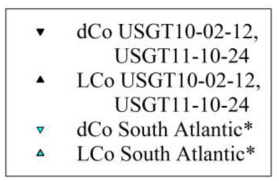

Figure 10. Aggregate nutrient stoichiometries between the North Atlantic and the South Atlantic studies. Basin offsets were observed in comparisons between (a) nitrate and phosphate (linear regression for South Atlantic with a slope of $17.4, r^{2}$ of 0.995$)$ and (b) cobalt and phosphate concentrations in the upper water column of the North and South Atlantic zonal sections (North Atlantic stations, 2-400 m, linear regression depths include 54-300 m, with a slope of $61.4, r^{2}$ of 0.90 ; South Atlantic stations 1-19, 54-300 m, same depths for linear regression, slope of 52.6, and $r^{2}$ of 0.83 ). (c) Different slopes and intercepts are observed across many regions of the world oceans that have been studied in the literature (Martin et al., 1989; Noble et al., 2012; Saito et al., 2010). (d) Linear relationships occur between cobalt and oxygen for USGT10, USGT11, and for previous work done in the South Atlantic. *Data from Noble et al. 2012.

Huntsman, 1995). The production of large GEOTRACES datasets provides an opportunity to explore this variability in stoichiometry and the processes behind them. Here, we describe broad regional differences in the Co: $\mathrm{P}$ relationships in the North Atlantic. A detailed and finer-scale analysis of these relationships and their ecological interpretations is discussed in a companion paper (Saito et al., 2017).

When the North and South Atlantic zonal datasets (USGT10/11 and CoFeMUG) were compared in an aggregate scatter plot (Fig. 10), there were two notable differences. First, there is a shift toward lower phosphate concentrations relative to cobalt concentrations in the North Atlantic when compared to the South Atlantic. This is likely due to the lower surface phosphate inventory observed in the North Atlantic relative to the South Atlantic (Noble et al., 2012; Wu et al., 2000), as was evident in comparisons of nitrate+nitrite versus phosphate on these two transects and the higher phosphate axis intercept in the South Atlantic (Fig. 10a). Second, there was also an offset in cobalt abundances, with a higher maximum of total dissolved cobalt in the North Atlantic that consistently approached $\sim 150 \mathrm{pM}$ (Fig. 2), likely due to the higher atmospheric cobalt flux and resultant concentrations in the North Atlantic relative to the South Atlantic. As mentioned earlier, the North Atlantic experiences significant aeolian input from the Sahara compared to the much lower dust inputs to the South Atlantic (Noble et al., 2012), and aeolian deposition is not considered to be a major source of phosphorus. This offset can also be seen in the $\mathrm{dCo}: \mathrm{O}_{2}$ plot as a vertical shift (Fig. 10d), also likely caused by the higher dust contribution in the North Atlantic and an overall greater inventory.

Dissolved labile cobalt (LCo) also showed linear relationships with phosphate in the North Atlantic (Fig. 11), where labile cobalt is defined as the sum of the free cobalt and the cobalt bound to weak ligands (Saito et al., 2004). Unlike the frequent observations of excess strong iron-binding ligands in oceanic photic zones (Buck, 2007; Buck et al., 2015; Rue and Bruland, 1997), strong cobalt-binding ligand concentrations tend to be less than or equal to total Co, allowing frequent detection of labile cobalt in the water column, and the potential for large swings in bioavailability of cobalt. In the water column below the upper photic zone, the slopes of the LCo: $\mathrm{P}$ trends (Fig. 11, black triangles, ranging 19$28 \mu \mathrm{mol} \mathrm{mol}{ }^{-1}$ ) are lower than those of the $\mathrm{dCo}: \mathrm{P}$ trends (Fig. 11, black circles, ranging $41-67 \mu \mathrm{mol} \mathrm{mol}^{-1}$ ). This is particularly intriguing as it contrasts an apparent steeper and less coherent LCo: $\mathrm{P}$ in the upper photic zone (Fig. 11, white triangles). The low labile cobalt in the upper photic zone was expected due to phytoplankton and microbial uptake, reflective of the scarcity of this labile cobalt form and resulting in it comprising a small fraction of total dissolved cobalt there. The correlation of labile cobalt with phosphate in the ocean interior implicates a remineralization source from decaying phytoplankton material. It is possible that cobalt taken up by phytoplankton and prokaryotic microbes for use in enzymes or vitamin $\mathrm{B}_{12}$ is present in a proteinaceous form intracellularly that is susceptible to degradation with proteolytic activity upon sinking and results in its release as labile cobalt. This would be in contrast to strongly complexed cobalt that is formed through insertion into corrin rings of the $\mathrm{B}_{12}$ precur- 


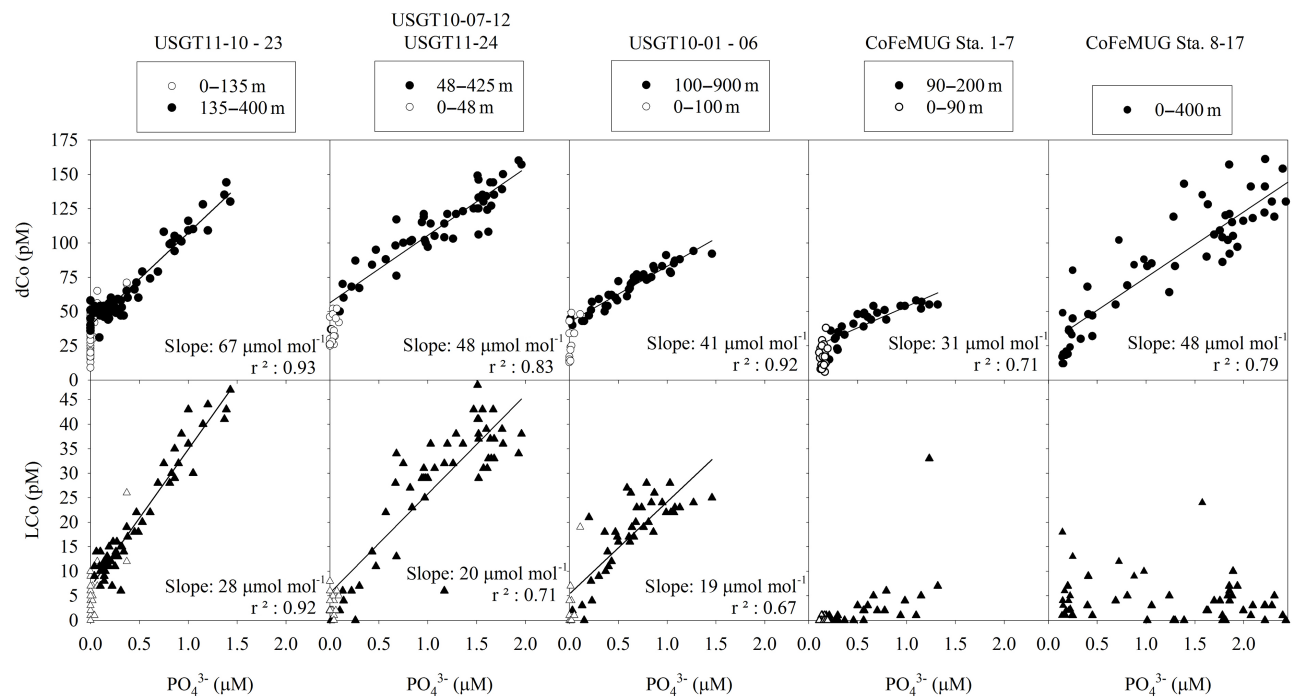

Figure 11. Co : P ecological stoichiometry observed across different regions in the North and South Atlantic. A tighter correlation is observed where labile cobalt becomes detectable and the correlation is observed down to differing depths depending on the strength of the processes that affect cobalt and phosphate biogeochemical cycling. Processes that affect both species similarly in time and space will tend to tighten the correlation and deepen the depth to which it is observed (e.g., USGT10-01-USGT10-06). Where scavenging or reductive dissolution may influence the two species differently, the correlation may be more diffuse or not observed at all (e.g., CoFeMUG Sta. 8-17).

sor by cobaltochelatase enzymes (Bonnet et al., 2010; Rodionov et al., 2003; Saito et al., 2005). This duality in cobalt's chemical forms, having both complexed and labile forms, adds a layer of variability in availability and geochemical cycling that is similar to that of dissolved and colloidal size fractions of iron (Bergquist et al., 2007; Fitzsimmons and Boyle, 2014). This fraction of the labile cobalt is likely a less protected inventory relative to scavenging processes, and even though it is a small component of the dissolved cobalt inventory, it could play a major role in cobalt biogeochemical cycling.

\subsubsection{Variation in the depth of the cobaltclines: evidence for dynamic biogeochemistry}

Examination of individual vertical profiles, with a focus on several stations from USGT10, further reveals the dynamic nature of cobalt chemical speciation and its influence on cobalt biogeochemical cycling in the photic zone of the North Atlantic (Fig. 12). With the exception of the labile cobalt at station USGT10-06, dissolved cobalt, labile cobalt and phosphate are all drawn down to their lowest concentrations in the mixed layer. By comparing these species to biological and physical proxies such as fluorescence and density, a few subtle differences emerge that are influenced by changes in the mixed layer depth and chlorophyll max. At all four stations, the gradient in total cobalt concentrations, or the "total cobaltcline" coincides with the base of the mixed layer (Fig. 12). At USGT10-09, the "phosphocline" and the "labile cobaltcline" also coincide with the base of the mixed layer. Here, the waters are particularly productive as seen by the intensity of the fluorescence peak, and the three analytes reach relatively high concentrations due to upwelling, potential aerosol inputs (Sect. 3.4.4), and sedimentary sources from the plume as discussed earlier (Sect. 3.4.1). The chlorophyll maximum was shallow and pressed up against the base of the mixed layer as a result of the upwelling.

We can compare this to the patterns observed at USGT1003 , where less productivity was observed due to a lack of significant external nutrient sources and correspondingly smaller local sub-mixed layer nutrient inventories (note the scale difference). Here, the total cobaltcline again coincides with the mixed layer depth $(77 \mathrm{~m})$, but phosphate and labile cobalt are both drawn down below detection, much deeper, into the middle of the chlorophyll maximum ( $99 \mathrm{~m}$, Fig. 12). In the other two stations as well, the chlorophyll maximum is smaller and deeper, and the labile cobaltcline follows the phosphocline, where the total cobaltcline remains coincident with the mixed layer depth, revealing a confluence of processes that are occurring on relatively short timescales. With a short residence time of 0.32 years in the upper water column (upper $100 \mathrm{~m}$; Saito and Moffett, 2002), the tug of war between biochemical and geochemical processes within one profile can be seen. This offset between the labile and total cobaltclines suggests that biological processes act quickly enough to complex labile cobalt that enters the chlorophyll maximum at a rate faster than upward mixing. While pigment samples from this transect were lost during freezer failure, making assessment of the biological contributions to these variations difficult, we know that generally the coastal regions of the Atlantic have more eukaryotic phytoplankton 

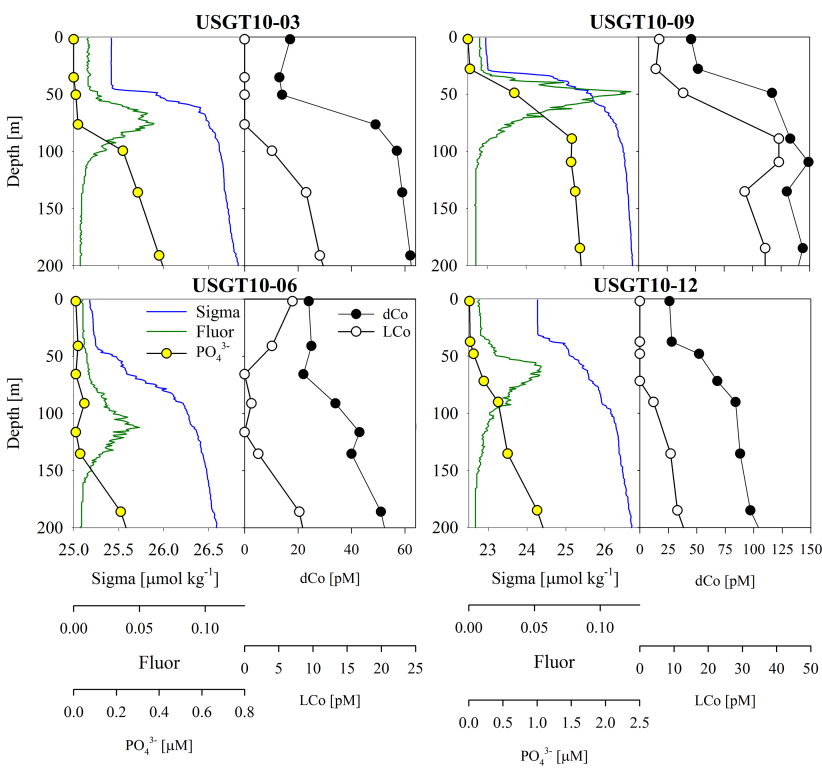

Figure 12. In the upper water column, labile cobalt is often drawn down above and within the chlorophyll maximum, following the phosphocline. The total cobaltcline appears to be more closely associated with mixed layer depth. Comparing stations that do and do not experience upwelling show that biological processes are capable of complexing labile cobalt at a rate faster than upward mixing. This is seen by comparing USGT10-03 (oligotrophic waters) to stations USGT10-12 (within the Mauritanian Upwelling). At both locations, labile cobalt is drawn down below detection into the chlorophyll maximum. Station USGT10-03 has a smaller deep inventory of cobalt $(\sim 50 \mathrm{pM}$ at the chlorophyll max, increasing to $\sim 60$ at $200 \mathrm{~m})$. Station USGT10-12 has a much larger deep inventory of cobalt $(\sim 70 \mathrm{pM}$ at the chlorophyll max, increasing to $\sim 100 \mathrm{pM}$ at $200 \mathrm{~m})$.

representation, while the oceanic regions are dominated by picocyanobacteria and picoeukaryotes (Olson et al., 1990), and that picocyanobacteria are sources of metal-binding ligands in both open ocean and coastal waters, including for cobalt and copper (Moffett and Brand, 1997; Saito et al., 2005). In the Mauritanian Upwelling, the inventories are higher and productivity is more intense, but the chlorophyll maximum is pressed up against the mixed layer, so the differences in rates of uptake, complexation, redox, diffusion, mixing, and upwelling cannot be easily separated.

\subsubsection{Loss of cobalt from intermediate and deep waters by scavenging}

In addition to the variety of sources that contribute cobalt to the North Atlantic described above, there is evidence for a dissolved sink from the pelagic water column throughout this North Atlantic zonal transect. This is evident in the vertical structure of profiles that, unlike nutrient-like elements such as phosphate and zinc, decrease precipitously at intermediate depths: below $\sim 1000 \mathrm{~m}$ in the western and northeastern At- lantic profiles and below $\sim 600 \mathrm{~m}$ in the eastern profiles off of Mauritania (Fig. 2). These changes in vertical structure likely reflect a shift in the balance between long-term scavenging removal processes occurring on horizontally advecting water masses relative to the vertical input of dissolved cobalt from remineralizing sinking particles. These scavenging processes can be observed in aggregate through an examination of the full-depth relationship between total dissolved cobalt and soluble reactive phosphorus ( $\mathrm{dCo}: \mathrm{P})$ across the basin that displayed a downward curl, reflective of a loss of total dissolved cobalt relative to phosphate consistent with a preferential scavenging of total dissolved cobalt (Fig. 13), likely into bacterially formed manganese oxide particles (Lee and Tebo, 1994; Moffett and Ho, 1996). Examination of the water masses calculated through OMPA (Jenkins et al., 2015) associated with data points in $\mathrm{dCo}: \mathrm{P}$ space showed water masses with unique signatures. In particular, the combined deep DSOW-AABW-ISOW ( $\sim 3000 \mathrm{~m}$ depth, Denmark Strait Overflow, Antarctic Bottom Water, and IcelandScotland Overflow) and CLSW ( 2000-3000 m, classical Labrador Seawater) water masses were the major contributors to the North Atlantic scavenged "curl" feature (Fig. 13a), implying loss of cobalt relative to phosphate in those water masses during their long-term advection. This cobalt curl feature is also evident in the South Atlantic zonal section as well, largely overlapping with the features observed here (Fig. 13c-d). Finally, the amount of dissolved cobalt at intermediate depths decreases from the North Atlantic to the South Atlantic, consistent with a scavenging loss with thermohaline circulation. The accompanying paper (Saito et al., 2017) conducts further statistical analysis and discussion of the scavenging process through a profile-by-profile examination of the $\mathrm{dCo}$ : $\mathrm{P}$ relationship.

Notably there were also instances where regional circulation influences the otherwise generally "typical" hybrid-type profile structure. For example, vertical structure was notably perturbed at station USGT10-07, where sharp concentration gradients appear coincident with jetting intrusions of water masses as indicated by oxygen concentration and water mass analysis (Jenkins et al., 2015) (Fig. 14).

\section{Conclusions}

The dissolved and labile cobalt datasets for the North Atlantic zonal transect reveal numerous sources of cobalt to the North Atlantic. A large plume of cobalt was observed at $\sim 400 \mathrm{~m}$ depth within the Mauritanian Upwelling along the eastern margin, which reflects eastern margin dissolved cobalt sources that are concentrated in the OMZ by phytoplankton uptake, export and remineralization and dust inputs. The western margin also displayed an elevated cobalt feature at intermediate depths characterized by ULSW, likely due to the mobilization of cobalt from continental shelf sediments either before or after subduction of the ULSW water mass. 
(a)
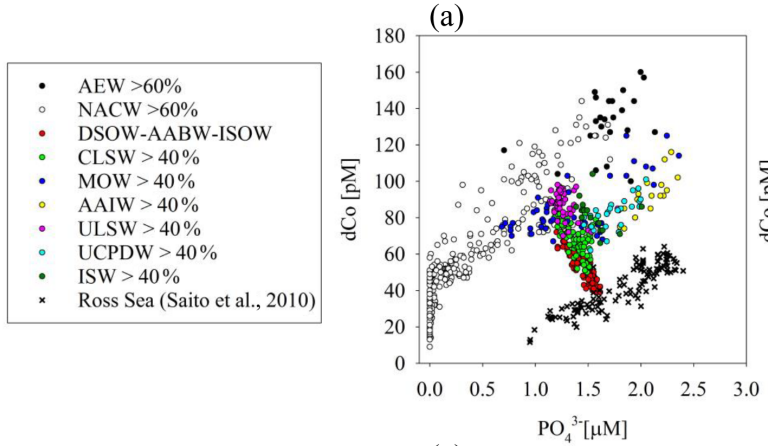

(c)

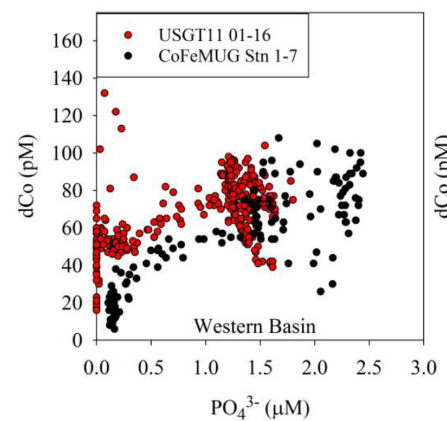

(b)

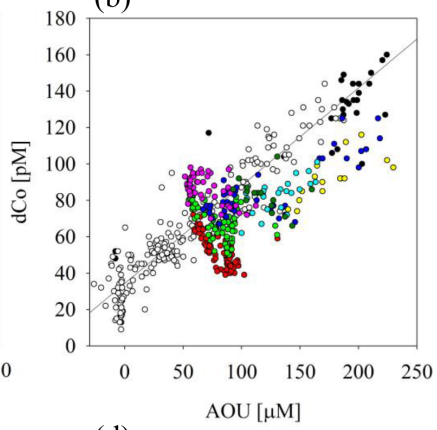

(d)

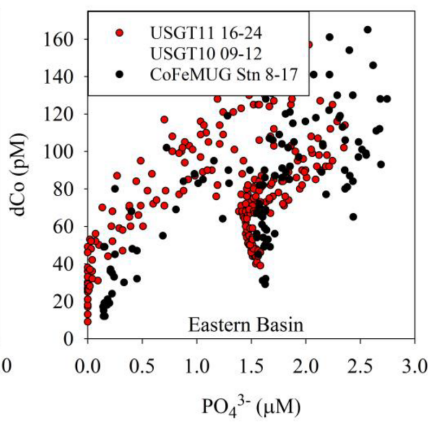

Figure 13. Full depth relationships of total dissolved cobalt, phosphate, and apparent oxygen utilization (AOU). In a comparison with water mass analysis from the GA03 expeditions, clear populations of data by water mass origin were observed in both (a) $\mathrm{dCo}: \mathrm{P}$ and (b) $\mathrm{dCo}$ : $\mathrm{AOU}$ space. Data from the Ross Sea is also shown as a potential end member (Saito et al., 2010). dCo : P relationships and the "cobalt curl" deviance from them were observed in the (c) western and (d) eastern basins of the Atlantic, and were similar between the North and South Atlantic (South Atlantic data from Noble et al., 2012).

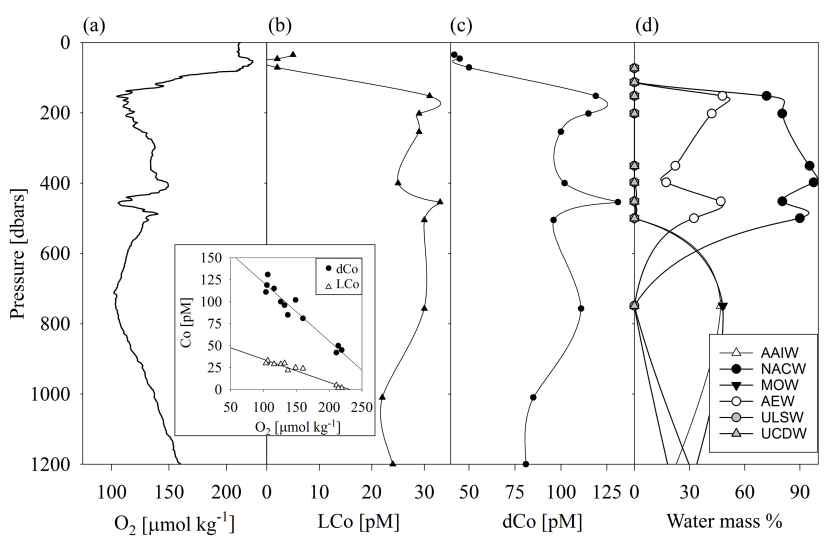

Figure 14. Intermediate depth profile for (a) $\mathrm{O}_{2}$, (b) labile cobalt (c) total cobalt and (d) water mass as a percent for USGT10-07. A strong linear correlation with $\mathrm{O}_{2}$ is observed (inset). A small but distinct maximum is observed between 400 and $600 \mathrm{~m}$ and demonstrates the capability of water mass features to influence the cobalt vertical profile at these depths.

Hydrothermal and aeolian sources were detectable but small relative to these larger ocean features. Variable sources and sinks of cobalt were observed in deep margin nepheloid layers, suggesting that particle composition and sediment redox gradients may play an important role and should be taken into consideration in future studies. Using deoxygenation rates and a relationship between cobalt and $\mathrm{O}_{2}$, we estimate that the cobalt inventory in the upper $1000 \mathrm{~m}$ of the North Atlantic may increase by $20 \%$ in the next 100 years due to ocean deoxygenation, approximately twice that estimated for the South Atlantic OMZ region. Differences in the ecological stoichiometry of cobalt observed in the upper water column imply that a wide variety of cobalt utilization regimes exist. The processes of uptake and remineralization exerted control on cobalt in the oligotrophic surface waters of the North Atlantic, demonstrated by correlations with phosphate, and the strong drawdown of phosphate, nitrate, and total dissolved and labile cobalt. When low-salinity, coastal, metal inputs and physical processes imposed a strong influence along Line W, these correlations were obscured, muting the influence of biological processes that operate to couple these species. Combining growing datasets of cobalt coming from the GEOTRACES program with future biochemical studies will improve our understanding of cobalt biogeochemical cycling and its interaction with ocean marine ecology.

Increasing anthropogenic cobalt use due to growth in the economic market for cobalt in lithium batteries and other sources poses the potential to drastically change global oceanic cobalt distributions since the potential environmen- 
tal impact of cobalt pollution is currently unknown. As such, it is more important than ever to establish a baseline understanding of cobalt distributions and cycling in the ocean to improve our ability to inform potential future impact of industrial use of cobalt on the ocean inventory.

Data availability. All information about the data used can be found in Sect. 2.3 and 2.4.

Author contributions. At-sea and laboratory analyses of total dissolved and labile cobalt were conducted by A. Noble. Data analysis and manuscript writing were conducted by A. Noble, M. Saito, and N. Hawco. Particulate sample collection, analyses, and interpretations in the text were conducted by P. J. Lam and D. Ohnemus.

Competing interests. The authors declare that they have no conflict of interest.

Acknowledgements. We would like to thank the GEOTRACES Expedition Team, including the chief scientists - Ed Boyle, Bill Jenkins, and Greg Cutter - and the GEOTRACES sampling team. We also thank the captain and crew of the R/V Knorr for their outstanding support of science. We also gratefully acknowledge support of funding agencies on the following grants: the US National Science Foundation (NSF-OCE 0928414, 1233261, 1435056) and the Gordon and Betty Moore Foundation (grant 3738).

Edited by: G. Herndl

Reviewed by: two anonymous referees

\section{References}

Ahlgren, N. A., Noble, A., Patton, A. P., Roache-Johnson, K., Jackson, L., Robinson, D., McKay, C., Moore, L. R., Saito, M. A., and Rocap, G.: The unique trace metal and mixed layer conditions of the Costa Rica upwelling dome support a distinct and dense community of Synechococcus, Limnol. Oceanogr, 59, 2166-2184, 2014.

Baars, O. and Croot, P. L.: Dissolved cobalt speciation and reactivity in the eastern tropical North Atlantic, Mar. Chem., 173, 310-319, 2015.

Banza, C. L. N., Nawrot, T. S., Haufroid, V., Decrée, S., De Putter, T., Smolders, E., Kabyla, B. I., Luboya, O. N., Ilunga, A. N., Mutombo, A. M., and Nemery, B.: High human exposure to cobalt and other metals in Katanga, a mining area of the Democratic Republic of Congo, Environ. Res., 109, 745-752, 2009.

Bergquist, B., Wu, J., and Boyle, E.: Variability in oceanic dissolved iron is dominated by the colloidal fraction, Geochim. Cosmochim. Acta, 71, 2960-2974, 2007.

Bonnet, S., Webb, E. A., Panzeca, C., Karl, D. M., Capone, D. G., and Wilhelmy, S. A. S.: Vitamin B12 excretion by cultures of the marine cyanobacteria Crocosphaera and Synechococcus, Limnol. Oceanogr., 55, 1959-1964, 2010.

Bowie, A. R., Whitworth, D. J., Achterberg, E. P., Fauzi, R., Mantoura, C., and Worsfold, P. J.: Biogeochemistry of Fe and other trace elements $(\mathrm{Al}, \mathrm{Co}, \mathrm{Ni})$ in the upper Atlantic Ocean, Deep Sea Res. I, 49, 605-636, 2002.

Bown, J., Boye, M., Baker, A., Duvieilbourg, E., Lacan, F., Le Moigne, F., Planchon, F., Speich, S., and Nelson, D. M.: The biogeochemical cycle of dissolved cobalt in the Atlantic and the Southern Ocean south off the coast of South Africa, Mar. Chem., 126, 193-206, 2011.

Bown, J., Boye, M., Laan, P., Bowie, A. R., Park, Y.-H., Jeandel, C., and Nelson, D. M.: Imprint of a dissolved cobalt basaltic source on the Kerguelen Plateau, Biogeosciences, 9, 5279-5290, https://doi.org/10.5194/bg-9-5279-2012, 2012a.

Bown, J., Boye, M., and Nelson, D. M.: New insights on the role of organic speciation in the biogeochemical cycle of dissolved cobalt in the southeastern Atlantic and the Southern Ocean, Biogeosciences, 9, 2719-2736, https://doi.org/10.5194/bg-9-27192012, 2012b.

Boyle, E. A., Anderson, R. F., Cutter, G. A., Fine, R., Jenkins, W. J., and Saito, M.: Introduction to the US GEOTRACES North Atlantic Transect (GA-03): USGT10 and USGT11 cruises, Deep Sea Res.II, 116, 1-5, 2015.

Bruland, K. W.: Oceanographic distributions of cadmium, zinc, nickel and copper in the North Pacific, Earth Planet. Sci. Lett., 47, 176-198, 1980.

Buck, C. S., Landing, W. M., and Resing, J. A.: Particle size and aerosol iron solubility: A high-resolution analysis of Atlantic aerosols, Mar. Chem., 120, 14-24, 2010.

Buck, K. N.: The physicochemical speciation of dissolved iron in the Bering Sea, Alaska, Limnol. Oceanogr., 52, 1800-1808, 1800, 2007.

Buck, K. N., Sohst, B., and Sedwick, P. N.: The organic complexation of dissolved iron along the U.S. GEOTRACES (GA03) North Atlantic Section, Deep Sea Res. II, 116, 152-165, 2015.

Cutter, G. A. and Bruland, K. W.: Rapid and noncontaminating sampling system for trace elements in global ocean surveys, Limnol. Oceanogr., 10, 425-436, 2012.

Duce, R. A., Liss, P. S., Merrill, J. T., Atlas, E. L., Buat-Menard, P., Hicks, B. B., Miller, J. M., Prospero, J. M., Arimoto, R., Church, T. M., Ellis, W., Galloway, J. M., Hansen, L., Jickells, T. D., Knap, A. H., Reinhardt, K. H., Schneider, B., Soudine, A., Tokos, J. J., Tsunogai, S., Wollast, R., and Zhou, M.: The Atmospheric Input of Trace Species to the World Ocean, Global Biogeochem. Cy., 5, 193-259, 1991.

Dulaquais, G., Boye, M., Middag, R., Owens, S., Puigcorbe, V., Buesseler, K., Masqué, P., Baar, H. J., and Carton, X.: Contrasting biogeochemical cycles of cobalt in the surface western Atlantic Ocean, Global Biogeochem. Cy., 28, 1387-1412, 2014a.

Dulaquais, G., Boye, M., Rijkenberg, M. J. A., and Carton, X.: Physical and remineralization processes govern the cobalt distribution in the deep western Atlantic Ocean, Biogeosciences, 11, 1561-1580, https://doi.org/10.5194/bg-11-1561-2014, 2014b.

Ellwood, M. J.: Wintertime trace metal $(\mathrm{Zn}, \mathrm{Cu}, \mathrm{Ni}, \mathrm{Cd}, \mathrm{Pb}$ and $\mathrm{Co}$ ) and nutrient distributions in the Subantarctic Zone between 40-52 ${ }^{\circ}$ S; 155-160 E, Mar. Chem., 112, 107-117, 2008.

Engelstaedter, S., Tegen, I., and Washington, R.: North African dust emissions and transport, Earth-Sci. Rev., 79, 73-100, 2006. 
Fitzsimmons, J. N. and Boyle, E. A.: Both soluble and colloidal iron phases control dissolved iron variability in the tropical North Atlantic Ocean, Geochim. Cosmochim. Acta, 125, 539-550, 2014.

Frame, C., Deal, E., Nevison, C., and Casciotti, K.: $\mathrm{N}_{2} \mathrm{O}$ production in the eastern South Atlantic: Analysis of $\mathrm{N}_{2} \mathrm{O}$ stable isotopic and concentration data, Global Biogeochem. Cy., 28, $1262-$ 1278, 2014.

German, C. R., Campbell, A. C., and Edmond, J. M.: Hydrothermal scavenging at the Mid-Atlantic Ridge: modification of trace element dissolved fluxes, Earth Planet. Sci. Lett., 107, 101-114, 1991.

Hansell, D. A. and Carlson, C. A.: Biogeochemistry of total organic carbon and nitrogen in the Sargasso Sea: control by convective overturn, Deep Sea Res. II, 48, 1649-1667, 2001.

Hatta, M., Measures, C. I., Wu, J., Roshan, S., Fitzsimmons, J. N., Sedwick, P., and Morton, P.: An overview of dissolved Fe and Mn distributions during the 2010-2011 U.S. GEOTRACES north Atlantic cruises: GEOTRACES GA03, Deep Sea Res. II, 116, 117-129, 2015.

Hawco, N. J., Ohnemus, D. C., Resing, J. A., Twining, B. S., and Saito, M. A.: A dissolved cobalt plume in the oxygen minimum zone of the eastern tropical South Pacific, Biogeosciences, 13, 5697-5717, doi:10.5194/bg-13-5697-2016, 2016.

Heggie, D. and Lewis, T.: Cobalt in pore waters of marine sediments, Nature, 311, 453-455, 1984.

James, R. H., Elderfield, H., and Palmer, M. R.: The chemistry of hydrothermal fluids from the Broken Spur site, $29^{\circ} \mathrm{N}$ MidAtlantic ridge, Geochim. Cosmochim. Acta, 59, 651-659, 1995.

Jenkins, W. J., Smethie Jr., W. M., Boyle, E. A., and Cutter, G. A.: Water mass analysis for the U.S. GEOTRACES (GA03) North Atlantic sections, Deep Sea Res. II, 116, 6-20, 2015.

Jickells, T. D.: The inputs of dust derived elements to the Sargasso Sea: a synthesis, Mar. Chem., 68, 5-14, 1999.

Jickells, T. D., Deuser, W. G., and Belastock, R. A.: Temporal Variations in the Concentrations of some Particulate Elements in the Surface of the Sargasso Sea and their Relationship to Deep-Sea Fluxes, Mar. Chem., 29, 203-219, 1990.

Johnson, K. S., Gordon, R. M., and Coale, K. H.: What controls dissolved iron in the world ocean?, Mar. Chem, 57, 137-161, 1997.

Kadko, D. and Johns, W.: Inferring upwelling rates in the equatorial Atlantic using 7 Be measurements in the upper ocean, Deep Sea Res. I, 58, 647-657, 2011.

Kadko, D., Landing, W. M., and Shelley, R. U.: A novel tracer technique to quantify the atmospheric flux of trace elements to remote ocean regions, J. Geophys. Res.-Oceans, 120, 848-858, 2015.

Keeling, R. F., Körtzinger, A., and Gruber, N.: Ocean deoxygenation in a warming world, Annu. Rev. Mar. Sci., 2, 199-229, 2010.

Kharkar, D. P., Turekian, K. K., and Bertine, K. K.: Stream supply of dissolved silver, molybdenum, antimony, selenium, chromium, cobalt, rubidium and cesium to the oceans, Geochim. Cosmochim. Acta, 32, 285-298, 1968.

Lacombe, H., Gascard, J., Gonella, J., and Bethoux, J.: Response of the Mediterranean to the water and energy fluxes across its surface, on seasonal and interannual scales, Oceanologica Acta, 4, 247-255, 1981.

Laës, A., Blain, S., Laan, P., Achterberg, E. P., Sarthou, G., and De Baar, H. J.: Deep dissolved iron profiles in the eastern North
Atlantic in relation to water masses, Geophys. Res. Lett., 30, https://doi.org/10.1029/2003GL017902, 2003.

Lam, P. J., Ohnemus, D. C., and Marcus, M. A.: The speciation of marine particulate iron adjacent to active and passive continental margins, Geochim. Cosmochim. Acta, 80, 108-124, 2012.

Lam, P. J., Ohnemus, D. C., and Auro, M. E.: Size-fractionated major particle composition and concentrations from the US GEOTRACES north Atlantic zonal transect, Deep Sea Res. II, 116, 303-320, 2015.

Lee, Y. and Tebo, B.: Cobalt(II) Oxidation by the Marine Manganese(II)-Oxidizing Bacillus sp. Strain SG-1, Appl. Environ. Microbiol., 60, 2949-2957, 1994.

Lippard, S. J. and Berg, J. M.: Principles in Bioinorganic Chemistry, University Science Books, Mill Valley, CA, 1994.

Mackey, K. R. M., Chien, C.-T., Post, A. F., Saito, M. A., and Paytan, A.: Rapid and gradual modes of aerosol trace metal dissolution in seawater, Front.n Microbiol., 5, 794, https://doi.org/10.3389/fmicb.2014.00794, 2014.

Mahowald, N. M., Baker, A. R., Bergametti, G., Brooks, N., Duce, R. A., Jickells, T. D., Kubilay, N., Prospero, J. M., and Tegen, I.: Atmospheric global dust cycle and iron inputs to the ocean, Global Biogeochem. Cy., 19, GB4025,https://doi.org/10.1029/2004GB002402, 2005.

Martin, J. H., Gordon, R. M., Fitzwater, S., and Broenkow, W. W.: VERTEX: phytoplankton/iron studies in the Gulf of Alaska., Deep-Sea Res., 36, 649-680, 1989.

Measures, C., Hatta, M., Fitzsimmons, J., and Morton, P.: Dissolved $\mathrm{Al}$ in the zonal $\mathrm{N}$ Atlantic section of the US GEOTRACES 2010/2011 cruises and the importance of hydrothermal inputs, Deep Sea Res. II, 116, 176-186, 2015.

Measures, C. I., Yuan, J., and Resing, J. A.: Determination of iron in seawater by flow injection analysis using in-line preconcentration and spectrophotometric detection, Mar. Chem., 50, 3-12, 1995.

Measures, C. I., Landing, W. M., Brown, M. T., and Buck, C. S.: High-resolution $\mathrm{Al}$ and $\mathrm{Fe}$ data from the Atlantic Ocean CLIVAR-CO2 Repeat Hydrography A16N transect: Extensive linkages between atmospheric dust and upper ocean geochemistry, Global Biogeochem. Cy., 22, GB1005, https://doi.org/10.1029/2007GB003042, 2008.

Metz, S. and Trefrey, J.: Chemical and mineralogical influences on concentrations of trace metals in hydrothermal fluids, Geochim. Cosmo. Acta, 64, 2267-2279, 2000.

Middag, R., Séférian, R., Conway, T. M., John, S. G., Bruland, K. W., and de Baar, H. J.: Intercomparison of dissolved trace elements at the Bermuda Atlantic Time Series station, Mar. Chem., 177, 476-489, 2015.

Moffett, J. W. and Brand, L. E.: Production of strong, extracellular $\mathrm{Cu}$ chelators by marine cyanobacteria in response to $\mathrm{Cu}$ stress, Limnol. Oceanogr., 41, 388-395, 1997.

Moffett, J. W. and Ho, J.: Oxidation of cobalt and manganese in seawater via a common microbially catalyzed pathway, Geochim. Cosmo. Acta, 60, 3415-3424, 1996.

Moore, C. M., Mills, M. M., Achterberg, E. P., Geider, R. J., LaRoche, J., Lucas, M. I., McDonagh, E. L., Pan, X., Poulton, A. J., Rijkenberg, M. J. A., Suggett, D. J., Ussher, S. J., and Woodward, E. M. S.: Large-scale distribution of Atlantic nitrogen fixation controlled by iron availability, Nature Geosci., 2, 867-871, 2009. 
Morley, N., Burton, J., Tankere, S., and Martin, J.-M.: Distribution and behaviour of some dissolved trace metals in the western Mediterranean Sea, Deep Sea Res. II, 44, 675-691, 1997.

Noble, A. E., Saito, M. A., Maiti, K., and Benitez-Nelson, C.: Cobalt, manganese, and iron near the Hawaiian Islands: A potential concentrating mechanism for cobalt within a cyclonic eddy and implications for the hybrid-type trace metals, Deep Sea Res. II, 55, 1473-1490, 2008.

Noble, A. E., Lamborg, C. H., Ohnemus, D., Lam, P. J., Goepfert, T. J., Measures, C. I., Frame, C. H., Casciotti, K., DiTullio, G. R., Jennings, J., and Saito, M. A.: Basin-scale inputs of cobalt, iron, and manganese from the Benguela-Angola front into the South Atlantic Ocean, Limnol. Oceanogr., 57, 989-1010, 2012.

Noble, A. E., Saito, M. A., Moran, D. M., and Allen, A.: Dissolved and particulate trace metal micronutrients under the McMurdo Sound seasonal sea ice: basal sea ice communities as a capacitor for iron, Front. Microbiol. Chem., 1, https://doi.org/10.3389/fchem.2013.00025, 2013.

Noble, A. E., Echegoyen-Sanz, Y., Boyle, E. A., Ohnemus, D. C., Lam, P. J., Kayser, R., Reuer, M., Wu, J., and Smethie, W.: Dynamic variability of dissolved $\mathrm{Pb}$ and $\mathrm{Pb}$ isotope composition from the US North Atlantic GEOTRACES transect, Deep Sea Res. II, 116, 208-225, 2015.

Ohnemus, D. C. and Lam, P. J.: Cycling of lithogenic marine particles in the US GEOTRACES North Atlantic transect, Deep Sea Res. II, 116, 283-302, 2015.

Ohnemus, D. C., Auro, M. E., Sherrell, R. M., Lagerstrom, M., Morton, P. L., Twining, B. S., Rauschenberg, S., and Lam, P. J.: Laboratory intercomparison of marine particulate digestions including Piranha: a novel chemical method for dissolution of polyethersulfone filters, Liminol. Oceanogr., 12, 530-547, 2014.

Olson, R. J., Chisholm, S. W., Zettler, E. R., Altabet, M. A., and Dusenberry, J. A.: Spatial and temporal distribution of prochlorophyte picoplankyon in the North Atlantic Ocean, Deep-Sea Res., 37, 1033-1051, 1990.

Redfield, A. C., Ketchum, B. H., and Richards, F. A. (Eds.): The Influence of Organisms on the Composition of Sea-Water, Wiley, 1963.

Rodionov, D. A., Vitreschak, A. G., Mironov, A. A., and Gelfand, M. S.: Comparative Genomics of the Vitamin B12 Metabolism and Regulation in Prokaryotes, J. Biol. Chem., 278, 4114841159, 2003.

Rue, E. L. and Bruland, K. W.: The role of organic complexation on ambient iron chemistry in the equatorial Pacific Ocean and the response of a mesocale iron addition experiment, Limnol. Oceanogr., 42, 901-910, 1997.

Saito, M.: Total dissolved Cobalt and labile Cobalt concentrations from R/V Knorr cruises KN199-04 and KN204-01 in the Subtropical northern Atlantic Ocean from 2010-2011 (U.S. GEOTRACES NAT project), Biological and Chemical Oceanography Data Management Office (BCO-DMO), Dataset version: 201304-26, available at: http://www.bco-dmo.org/dataset/3868, 2013.

Saito, M. A. and Goepfert, T. J.: Zinc-cobalt colimitation in Phaeocystis antarctica, Limnol. Oceanogr., 53, 266-275, 2008.

Saito, M. A. and Moffett, J. W.: Complexation of cobalt by natural organic ligands in the Sargasso Sea as determined by a new highsensitivity electrochemical cobalt speciation method suitable for open ocean work, Mar. Chem., 75, 49-68, 2001.
Saito, M. A. and Moffett, J. W.: Temporal and spatial variability of cobalt in the Atlantic Ocean, Geochim. Cosmochim. Acta, 66, 1943-1953, 2002.

Saito, M. A., Moffett, J. W., and DiTullio, G.: Cobalt and Nickel in the Peru Upwelling Region: a Major Flux of Cobalt Utilized as a Micronutrient, Global Biogeochem. Cy., 18, GB4030, https://doi.org/10.1029/2003GB002216, 2004.

Saito, M. A., Rocap, G., and Moffett, J. W.: Production of cobalt binding ligands in a Synechococcus feature at the Costa Rica Upwelling Dome, Limnol. Oceanogr., 50, 279-290, 2005.

Saito, M. A., Goepfert, T. J., Noble, A. E., Bertrand, E. M., Sedwick, P. N., and DiTullio, G. R.: A seasonal study of dissolved cobalt in the Ross Sea, Antarctica: micronutrient behavior, absence of scavenging, and relationships with $\mathrm{Zn}, \mathrm{Cd}$, and P, Biogeosciences, 7, 4059-4082, https://doi.org/10.5194/bg-7-40592010, 2010.

Saito, M. A., Noble, A. E., Tagliabue, A., Goepfert, T. J., Lamborg, C. H., and Jenkins, W. J.: Slow-spreading submarine ridges in the South Atlantic as a significant oceanic iron source, Nature Geosci., 6, 775-779, 2013.

Saito, M. A., Noble, A., Hawco, N., Twining, B. S., Ohnemus, D. C., John, S. G., Lam, P., Conway, T. M., Johnson, R., Moran, D., and McIlvin, M.: The Acceleration of Dissolved Cobalt's Ecological Stoichiometry due to Biological Uptake, Remineralization, and Scavenging in the Atlantic Ocean, Biogeosciences Discuss., https://doi.org/10.5194/bg-2016-511, in review, 2016.

Schlitzer, R.: Ocean Data View, version 4.4.2 [Internet], available at: http://odv.awi.de (last access: May 2017), 2011.

Scrosati, B. and Garche, J.: Lithium batteries: Status, prospects and future, Journal of Power Sources, 195, 2419-2430, 2010.

Shelley, R., Sedwick, P. N., Bibby, T., Cabedo-Sanz, P., Church, T., Johnson, R., Macey, A., Marsey, C., Sholkovitz, E., Ussher, S., and Worsfold, P.: Controls on dissolved cobalt in surface waters of the Sargasso Sea: Comparisons with iron and alumnium, Global Biogeochem. Cy., 26, GB2020, https://doi.org/10.1029/2011GB004155, 2012.

Shelley, R. U., Wyatt, N. J., Tarran, G. A., Rees, A. P., Worsfold, P. J., and Lohan, M. C.: A tale of two gyres: Contrasting distributions of dissolved cobalt and iron in the Atlantic Ocean during an Atlantic Meridional Transect (AMT-19), Prog. Oceanogr., https://doi.org/10.1016/j.pocean.2016.10.013, 2016.

Shelley, R. U., Morton, P. L., and Landing, W. M.: Elemental ratios and enrichment factors in aerosols from the US-GEOTRACES North Atlantic transects, Deep Sea Res. II, 116, 262-272, 2015.

Skogen, M.: A biophysical model applied to the Benguela upwelling system, South African Journal of Marine Science, 21, 235-249, 1999.

Steinberg, D. K., Carlson, C. A., Bates, N. R., Johnson, R. J., Michaels, A. F., and Knap, A. H.: Overview of the US JGOFS Bermuda Atlantic Time-series Study (BATS): a decade-scale look at ocean biology and biogeochemistry, Deep Sea Res. II, 48, 1405-1447, 2001.

Sterner, R. W. and Elser, J. J.: Ecological Stoichiometry: The Biology of Elements from Molecules to the Biosphere, Princeton University Press, Princeton NJ, 2002.

Stramma, L., Johnson, G. C., Sprintall, J., and Mohrholz, V.: Expanding Oxygen-Minimum Zones in the Tropical Oceans, Science, 320, 655-658, 2008. 
Sunda, W. and Huntsman, S. A.: Cobalt and zinc interreplacement in marine phytoplankton: Biological and geochemical implications, Limnol. Oceanogr., 40, 1404-1417, 1995.

Swanner, E. D., Planavsky, N. J., Lalonde, S. V., Robbins, L. J., Bekker, A., Rouxel, O. J., Saito, M. A., Kappler, A., Mojzsis, S. J., and Konhauser, K. O.: Cobalt and marine redox evolution, Earth Planet. Sci. Lett., 390, 253-263, 2014.

Taylor, S. R. and McLennan, S. M.: The Continental Crust: its Composition and Evolution, Blackwell Scientific Publications, Boston, 1985.
Thuróczy, C.-E., Boye, M., and Losno, R.: Dissolution of cobalt and zinc from natural and anthropogenic dusts in seawater, Biogeosciences, 7, 1927-1936, https://doi.org/10.5194/bg-7-19272010, 2010.

Wu, J., Sunda, W., Boyle, E. A., and Karl, D. M.: Phosphate Depletion in the Western North Atlantic Ocean, Science, 289, 752-762, 2000.

Zhang, H., Van den Berg, C. M. G., and Wollast, R.: The Determination of Interactions of Cobalt (II) with Organic Compounds in Seawater using Cathodic Stripping Voltammetry, Mar. Chem., 28, 285-300, 1990. 